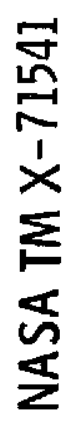

(AASA-TA-X-71541) EXTERNALLY BLOWN FLAP NOISE RESEARCH (NASA), 44 p HC $\$ 5.25$ CSCL $01 \mathrm{C}$

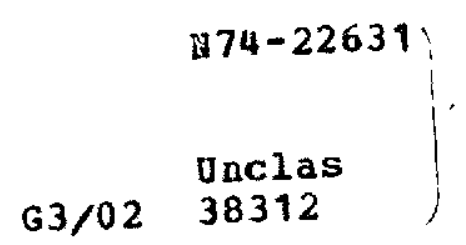

\title{
EXTERNALLY BLOWN FLAP NOISE RESEARCH
}

by Robert G. Dorsch

Lewis Research Center

Cleveland, Ohio

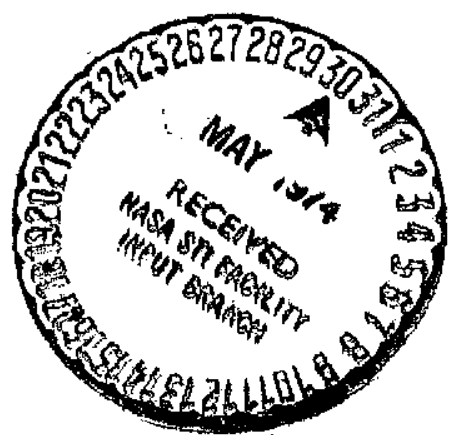

TECHNICAL PAPER proposed for presentation at the National Air Transportation Meeting sponsored by The Society of Automotive Engineers Dallas, Texas, April 30 - May 2, 1974 
$\frac{1}{\text { EXTERNALLY BLOWN FLAP NOISE RESEARCH }}$

by Robert G. Dorsch

Lewis Research Center

\begin{abstract}
The Lewis Research Center cold-flow model externally blown flap (EBF) noise research test program is summarized. Both engine under-the-wing and over-the-wing EBF wing section configurations were studied. Ten large scale and nineteen small scale EBF models were tested. A limited number of forward airspeed effect and flap noise suppression tests were also run. The key results and conclusions drawn from the flap noise tests are summarized and discussed.
\end{abstract}

\title{
INTRODUCTION
}

The use of powered lift for short-haul and STOL aircraft applications is currently under consideration. The externally blown flap (EBF) has long been recognized as one of the simpler ways to achieve powered lift (e.g., refs. 1 to 3 ). Both engine-under-the-wing (UTW) and engine-overthe-wing (OTW) configurations are being examined (fig. 1). Unfortunately, a considerable amount of noise is produced as the engine exhaust interacts with the surfaces of the flap system (refs. 4 and 5).

The flap interaction noise produced by EBF systems can be the dominant noise source when highly noise-suppressed turbofan engines are employed. This noise is in direct conflict with the stringent noise goals being put forth for powered lift aircraft. For example, a 500-foot sideline noise goal of 95 EPNAB has of ten been discussed.

During the past three years extensive research and development activity has been initiated by the National Aeronautics and Space Administration to measure, define, and predict the flap interaction noise field for a variety of $\mathrm{EBF}$ configurations and to provide insight into flap noise source mechanisms (refs. 5 to 19). These effects have been accompanied by special tests and programs aimed at suppressing flap notse (refs. 20 to 27 ).

Initially most of the research and development effort was directed towards the UTW system because such an aircraft could more readily be evolved from current commercial CTOL aircraft. However, as the magnitude of the flap noise problem became more clearly understood there was increased interest in establishing the acoustic characteristics of OTW EBF systems (refs. 14 and 28 to 37 ). The OTW system takes advantage of the high frequency acoustic shielding provided by the wing and flap system. 
As part of this research program the NASA Lewis Research Center has conducted a large number of in-house EBF noise tests using both small and large scale cold-flow (ambient temperature) models. Both UTW and OTW EBF models having a wide variety of geometrical configurations were employed. The test configurations included simulations of both conventional (1ow jet-velocity-decay) and mixer-decayer (high jet-velocity-decay) engine exhaust nozzles.

In addition to these cold-flow model tests a program was conducted to obtain flap noise data with EBF models employing a turbofan engine to blow the flaps (refs. 38 and 39 ). This Lewis program is summarized in a companion paper (ref. 40) for this meeting.

The purpose of this paper is to summarize the key results and conclusions drawn from the Lewis Research Center cold-flow EBF model noise tests.

\section{LEWIS COLD-FLOW-MODEL TESTS}

\section{Flap Noise Test Facilities}

The cold-flow externally blown flap model noise test program was conducted at the Lewis Research Center with two basic facilities which were conceptually similar but differed in size.

Sma11-scale-model rig. - The sma11-scale cold-flow EBF test facility is shown in figure 2. The flow system and microphone circle are shown in figure 2(a). The engine exhaust was simulated by an air jet from a nozzle having a nominal diameter of $2 \mathrm{in.}$ The nozzle was supplied by dried pressurized air at a nominal temperature of $60^{\circ} \mathrm{F}$ brought to the test site by a 24-in. underground 1ine. The nozzle air supply system consisted of (proceeding downstream) a flow measuring orifice, a flow control valve, two perforated plates, a four-chamber baffled muffler, a $23 \mathrm{ft}$ 1ong, 4-in. diameter inlet pipe and, finaliy, the nozzle. The muffler was employed to remove internally generated noise (valve, etc.).

Typical under-the-wing (UTW) and over-the-wing (OTW) EBF models are shown in figures $2(b)$ and (c), respectively. The basic wing section model employed had a chord length of $13 \mathrm{in.}$ and a section span of $24 \mathrm{in.}$ The UTW model shown in figure 2 (b) had a 2.06 in. diameter conical nozzle and a double slotted flap system. The OTW model of figure 2 (c) had an orificesimulated 8-lobe mixer-decayer nozzle (2.4 in. equivalent diam.) plus an exhaust flow deflector to promote attachment to the wing and flap system (slots covered).

Sound data were taken by microphones placed on a 10-ft radius circle centered at the nozzle exit. The microphone plane and jet centerline were located $5 \mathrm{ft}$ above the ground. The EBF models were designed so that they could be rotated about the nozzle centerline axis (fig. 2(b)). F1yover noise was measured with the wing-flap system oriented vertically and making a $90^{\circ}$ angle with the horizontal microphone plane $\left(\phi=90^{\circ}\right.$, fig. $\left.2(\mathrm{a})\right)$. 
Sideline noise measurements were taken with the wing-flap system making either a $5^{\circ}$ angle or a $26.5^{\circ}$ angle with the microphone plane.

Large-scale-model rig. - The large scale cold-flow EBF test facility is shown in figure 3. The airflow system is shown schematically in figure $3(\mathrm{a})$. Dry ambient temperature air $\left(45^{\circ}\right.$ to $\left.80^{\circ} \mathrm{F}\right)$ was supplied to a 16-in. diameter gate shutoff valve through an underground pipeline from the Center's air supply system (150 psig max). Air flow rate and nozzle pressure ratio (nozzle total pressure divided by ambient atmospheric pressure) were set by adjustment of a 10-in. diameter butterfly flow control valve.

A muffler system installed in the line downstream of the flow control valve attenuated internal noise caused primarily by the flow control valve. Essentially, the muffler system consisted of perforated plates and dissipative type mufflers. The perforated plates were located immediately downstream of the flow control valve ( 40 percent open area) and at the entrances and exit of the first dissipative muffler (20 percent open area). Both mufflers were sections of pipe that housed crossed splitter plates oriented at right angles to one another so that the flow was divided into four channels. All internal surfaces of the muffler pipes and surfaces of the splitter plates were covered with acoustic absorbent material. The second muffler was located downstream of the last $45^{\circ}$ elbow in the air flow Iine to take advantage of the reflections caused by turning the flow. In addition, the flow system was wrapped externally with fiberglass and leaded vinyl sheet to impede direct radiation of internal noise through the pipe wal1.

Two screens were placed in the air line downstream of the last muffler to improve the flow distribution to the nozzle. Total pressure and temperature were measured directly upstream of the nozzle. Nozzle exhaust velocities were calculated from the isentropic gas dynamic equations assuming fully expanded flow.

Typical under-the-wing and over-the-wing EBF models are shown in figures $3(b)$ and (c), respectively. The basic large-scale wing model had a 7 foot chord length and a section span length of $9 \mathrm{ft}$. The large models were generally 6.5 times as large as equivalent models run on the small scale rig. The UTW model shown in figure $3(\mathrm{~b})$ was a three-flap configuration with a multi-lobed mixer decayer nozzle having an equivalent diameter of $15.75 \mathrm{in.}$ The OTW model shown in figure $3(\mathrm{c})$ was a two-flap configuration (slots covered) having a 13-in. conical nozzle with a flow deflector. The EBF models were mounted vertically with the nozzle centerline axis $12.75 \mathrm{ft}$ above grade as shown in. figure $3(\mathrm{a})$.

The microphone layout used for the large model tests is shown in figure 3(d). Up to twenty microphones were placed in a $50 \mathrm{ft}$ circle in a plane parallel to the ground and passing through the nozzle centerline (flyover plane). Noise measurements were also taken at selected angles in the sideline plane as shown in figure 3(d) with microphones suspended from a boom. 
Acoustic instrumentation and analysis. - Noise measurements on both rigs were made with $1 / 2-i n$. condenser microphones. The noise data were analyzed by a 1/3-octave-band spectrum analyzer which determined sound pressure leve1 spectra referenced to 0.0002 microbar. Three samples of data were taken at each microphone, averaged, and corrected for atmospheric attenuation to give lossless sound pressure level data. All data in this report are lossless unless stated otherwise. Overa11 sound pressure levels were calculated from the lossless SPL data. The data presented herein do not include ground reflection corrections unless specifically stated that they were made. In these cases the ground effect corrections were usually made by the method of reference 19. Sound power levels (when computed) were referenced to $10^{-13}$ watts.

\section{Sma11-Scale Lift-Thrust Facility}

Zero-forward-velocity (static) lift and thrust data were obtained for many of the smal1-scale nozzle and wing-flap configurations that were tested for noise characteristics. The lift and thrust data were obtained on a separate facility which is described more fully in reference 21 . The force measuring system was isolated from the nozzle air supply system by sending the pressurized air through twin supply lines into a plenum through flexible couplings. The plenum, nozzle, and wing-flap system were free to move in a horizontal plane and in the axial direction. The plenum and model weight was supported by an overhead-cable suspension system. Forward-thrust was measured by a load cell on the nozzle axis upstream of the plenum. Lift was measured by load cell in the same hor $1-$ zontal plane as the axis but perpendicular to it. A 5 to 1 slot nozzle configuration is shown in figure 4 (a) mounted in the rig. The traversing probe shown in the figure was used for velocity surveys in the trailing edge region of the wing.

Examples of the type of data obtained are shown in figure 4(b) (from ref. 31). Measured static turning effectiveness for some OTW EBF models with different types of nozzles and flow attachment devices are shown. The flap slots were covered in all cases.

\section{Summary of Models Tested}

Acoustic tests. - The research objectives of the externally blown flap model acoustic tests were twofold: (1) to perform configuration screening tests on a variety of models (mostly on the small scale facility); and (2) to obtain a more complete set of test data on a limited number of basic and/or practical configurations. The latter tests were generally done with both large and small scale models so that information on noise scaling laws for flap noise was also obtained.

The Lewis cold-flow externally blown flap model acoustic tests run to date are summarized in table I. In all, a total of 29 different UTW and OTW EBF models were tested in either the large-scale or the smal1- 
scale flap noise test facility. A rather extensive set of noise data were taken with 2-flap UTW models $\|_{1} 1$, 33 , 非, 10 , and 非15 and with OTW models $\#_{17}$, 非 8 , and $\# 19$ of table I. Fairly complete noise data were also taken with 3-flap UTW models $\$ 2$, \#4, and $\# 9$. The remaining models listed in table I were employed primarily for configuration screening studies.

The results of the noise tests for the models of table I have been summarized in the references listed.

Flap noise source suppression tests. - In addition to the acoustic tests of table I, more recent special tests have been run to study flap nolse source suppression techniques. These models are listed in table II. The large-model 13-in. diameter conical nozzle 2-flap tests (mode1 非 table I) were repeated with special sets of flaps equipped with a variety of suppression devices. These models are listed as $\|_{1} 1$ through $\$ 4$ in table II. In addition to the large-model tests, a limited number of small mode1 tests were run ("\#'s 5 to 7 of table II) using specially equipped flat plate and wing-flap models. The flat plate trailing edge blowing results were reported in reference 26 and the remaining tests have not yet been published.

\section{CORRELATION AND SCALING PARAMETERS}

\section{UTW-EBF Configurations}

With the engine under the wing, the flap interaction noise measured in the forward quadrant below the wing $\left(\theta=0^{\circ}\right.$ to $90^{\circ}$ in fig. $2(a)$ ) is dominated by the dipole noise field associated with the fluctuating pressures generated on the flap surfaces by the impinging turbulent exhaust jet (ref. 16). The overall sound pressure level measured in this region has been found to vary as the sixth power of the peak flap impingement velocity, $V_{i, p}$, and as the first power of the exhaust plume impingement area, $A_{i}$ (refs. 16 and 24). In these references the impingement area at the flap axial station, $A_{i}$, was determined (arbitrarily) from the width of the velocity profile curve where the velocity is down to 80 percent of the peak value, $v_{i, p}$.

A typical impingement profile for a single-element nozzle (e.g., a conical nozzle) is shown along with a sketch of $A_{i}$ and the projected flap area in figure 5(a). Assuming (as shown in fig. 5(a)) that the entire flow within the high velocity region hits the flaps, then the RMS acoustic pressure, $p$, can be represented by the following relation (ref. 16).

$$
\mathrm{p}^{2} \sim\left(\frac{\mathrm{\rho}_{\mathrm{o}}}{\mathrm{C}_{\mathrm{o}}}\right)^{2} \frac{\mathrm{A}_{\mathrm{i}}}{\mathrm{R}^{2}} \mathrm{v}_{i, \mathrm{p}}^{6}
$$


where $R$ is the microphone distance, $\rho_{0}$ is the ambient density, and $C_{0}$ is the ambient speed of sound.

Multitube or multilobed nozzles (fig. 3(b)) usually have multi-peaked velocity profiles, and therefore more than one high-velocity region impinging on the flaps, as shown in figure 5(b). For these, cases, $A_{i}$ is obtained from the sum of the local high velocity areas $A_{i}^{\prime}$ which actually impinge on the flaps. Local high velocity areas missing the flaps are not included as illustrated in figure $5(\mathrm{~b})$.

Detailed exhaust velocity profile data are required to use equation (1). In many instances these data are not available for making comparisons or predictions of flap noise. Further, it was shown in reference 16 that an additional impingement parameter related to the turbulence intensity was required to correlate flap noise data from two-stream (coaxial) nozzle EBF systems with data from single stream (e.g., conical) nozzle EBF systems.

Both of these problems can be bypassed (with some loss of accuracy by using the nozzle exit parameter relations of references 18 and 16 to correlate the data. That is, expression (1) can be rewritten in terms of exhaust flow parameters defined at the nozzle exit station as follows:

$$
\mathrm{p}^{2} \sim\left(\frac{\rho_{\mathrm{o}}}{\mathrm{C}_{\mathrm{o}}}\right)^{2} \frac{\mathrm{A}_{\mathrm{T}}}{\mathrm{R}^{2}} \mathrm{v}_{\mathrm{E}}^{\mathrm{n}}
$$

where

$$
A_{T}=A_{C}+A_{F}
$$

and

$$
V_{E}=\left(\frac{{ }_{C} V_{C}^{6}+A_{F} V_{F}^{6}}{A_{T}}\right)^{1 / 6}
$$

and $\mathrm{A}_{\mathrm{C}}$ is the core nozzle exit area, $\mathrm{A}_{\mathrm{F}}$ is the fan (or annular) nozzle exit area, $V_{C}$ is core nozzle exhaust velocity, and $V_{F}$ is the fan (or annular) nozzle exhaust velocity. The exponent, $n$, of the effective exhaust velocity, $\mathrm{V}_{\mathrm{E}}$, is an empirical constant having a value between 6 and 7. For single-stream conical nozzles, $V_{E}=V$ where $V$ is simply the nozzle exhaust velocity, and $A_{T}$ becomes $A_{N}$ the nozzle exit area.

The use of equation (2) to correlate flap noise data must be limited to comparing data from EBF systems employing nozzles having either very small (or else having very similar) exhaust velocity decay and spreading characteristics. If it is desired, for example, to correlate EBF data from systems having mixer-decayer nozzles with data from systems having 
more conventional low-decay nozzles it is necessary to use the impingement parameters of relation (1).

\section{OTW-EBF Configurations}

The Lewis cold-flow model OTW data have, to date, been taken with EBF systems employing single-stream nozzles only (table I). These data have been correlated in terms of nozzle exit flow parameters and generally correlate quite well with the sixth power of the nozzle exhaust velocity, V (ref. 33). Therefore equation (2) can be used in the form

$$
\mathrm{p}^{2} \sim\left(\frac{\rho_{\mathrm{o}}}{\mathrm{C}_{\mathrm{o}}}\right)^{2} \frac{\mathrm{A}_{\mathrm{N}}}{\mathrm{R}^{2}} \mathrm{v}^{6}
$$

to correlate the OTW flap noise data.

The use of equation (5) assumes that exhaust velocity-decay does not play an important role in OTW configurations because the exhaust nozzle exit is generally in close proximity to the wing.

ENGINE UNDER THE WING RESULTS

\section{Flap Noise Field in Flyover Plane}

Typical flap noise test results will first be discussed for the measurements made in the flyover plane. The flyover plane was defined in figures $2(a)$ and $3(d)$. These results are important because they define the flap noise field below the EBF models. This information is needed to assess (or predict) the flyover noise for future powered lift aircraft.

Noise radiation pattern. - A typical UTW blown flap noise radiation pattern at 50 foot radius is shown in figure 6 (taken from ref. 6). The data were taken in the flyover plane of figure $3(d)$. The data were obtained with model $\# 1$ of table I (a 7 ft chord 2-flap model with a coaxial nozzle). The core exhaust velocity was $765 \mathrm{ft} / \mathrm{sec}$ and the annular nozzle (fan) exhaust velocity was $582 \mathrm{ft} / \mathrm{sec}$. The overall sound pressure level (OASPL) as a function of microphone angle, $\theta$, is given for flap positions of $30^{\circ}-60^{\circ}, 10^{\circ}-20^{\circ}$, and $0^{\circ}$ (fully retracted) and for the nozzle alone. Figure 6 shows the large increase in noise observed below the wing as the flaps are lowered into the exhaust stream of the nozzle. With the trailing flap at the maximum deflection angle of $60^{\circ}$, the noise is particularly intense in the forward quadrant below the wing. In this region the dipole noise radiating from the flap surfaces is dominant. As indicated earlier the dipole noise is caused by fluctuating pressures on the flap surfaces which in turn are caused by the impinging exhaust flow.

Sound pressure level spectra. - The 1/3-octave-band sound pressure level (SPL) flap noise spectra measured at $85^{\circ}$ from the inlet in the fly- 
over plane for the same model and test conditions as given in figure 6 are shown in figure 7 (taken from ref. 6). The spectra (corrected for ground effects) are broadband and similar in appearance to jet noise spectra. The strong increase in low frequency noise as the flaps are lowered from the retracted position to the $60^{\circ}$ setting is readily apparent.

The effect of model size and nozzle exhaust velocity on the SPL spectra can be taken into account by using the Strouhal relation between one-third octave band center frequency, $f$, nozzle equivalent diameter (based on $A_{T}$ ), $D_{T}$, and effective exhaust velocity, $V_{E}$. The normalized sound pressure level spectral density (SPL - OASPL + $1010 \mathrm{~g} \mathrm{~V}_{\mathrm{E}} / \mathrm{D}_{\mathrm{T}}$ - $10 \log \Delta \mathrm{f}$ ) for the $70^{\circ}$ microphone is plotted as a function of Strouhal number ( $f \mathrm{D}_{T} / \mathrm{V}_{\mathrm{E}}$ ) for four of the large scale models in figure 8 (taken from ref. 16). The data have been corrected for ground effects and are for the conical nozzle and coaxial nozzle two and three flap models (非 to \#4) of table I. Each curve shown in figure 8 was obtained by fairing a smooth curve through a set of points calculated from data for five different exhaust velocities in the range of 450 to $1000 \mathrm{ft} / \mathrm{sec}$. The $70^{\circ}$ angle was chosen because it yields the flyover maximum flap noise for these configurations. Figure 8 shows that the type of nozzle employed (conical or coaxial) did not change the spectral shape. Although the curves are displaced, the shape of the spectra for both the two- and three-flap models were very similar for the two types of nozzles. The two-flap spectra of figure 8 are somewhat broader and less peaked than the three-flap spectra; however, the differences are fairly small.

Variation of OASPL with exhaust velocity. - As pointed out earlier the flap noise level is dependent on the nozzle exhaust velocity (eq. (2)). Flap noise data for four 2-flap EBF configurations having low velocitydecay nozzles are correlated in figure 9 (taken from ref. 16) in terms of exhaust flow parameters defined at the nozzle exit station. The normalized overall sound pressure leve1 (OASPL - $10 \log \mathrm{A}_{\mathrm{T}}$ ) for the $70^{\circ}$ microphone is plotted as a function of the effective nozzle exhaust velocity for models $\# 3$, 非, \#6, and 1 , 1 of table $I$. These models have different types of exhaust nozzles and have different nozzle exit areas. The slope of the curve drawn through the data indicates a velocity power exponent of about 6.7. Further, it is clear from figure 9 that while the OASPL for the flap noise is dependent on nozzle exit area and on effective exhaust velocity, it is not dependent on the type of nozzle used ffor low velocity-decay type nozzles). The data for the conical, plug, and coaxial nozzle EBF configurations are correlated quite we11 by the use of nozzle area and exhaust parameters alone.

Equation (1) indicates that flap noise data should correlate very well in terms of exhaust impingement parameters measured at the flap station. Normalized overall sound pressure level (OASPL - $10 \log A_{i}(50 / R)^{2}$ ) for 2-flap models (非3, \#5, \#6, and $\# 10$ of table I) having single stream (conical and plug) nozzles and $60^{\circ}$ trailing flap position are plotted at the angle corresponding to the radial peak value as a function of the peak impingement velocity, $V_{i, p}$, in figure 10 (from ref. 16). The OASPL 
in figure 10 is normalized using the impingement area, $A_{i}$ (normalized to $1 \mathrm{ft}^{2}$ ), as the area parameter instead of the nozzle exhaust exit area, $\mathrm{A}_{\mathrm{T}}$, as in figure 9. The microphone radius term $(50 / \mathrm{R})^{2}$ was included because the small scale data were measured at $10 \mathrm{ft}$ instead of $50 \mathrm{ft}$. Figure 10 shows that the parameters $A_{1}$ and $V_{i, p}$ correlate the singleelement nozzle data very well. Further, the data can now be fitted by a sixth power of velocity curve instead of the 6.7 power required to fit the data using nozzle exhaust parameters. Thus, the use of impingement parameters in the correlation gives very good agreement with the simple dipole source mode1 (eq. (1)).

The impingement parameter method offers the advantage that flap noise for EBF configurations having exhaust nozzles with both high and low exhaust-velocity-decay rates can be correlated by a single set of parameters as shown in figure 11 (taken from ref. 24). In figure 11 the normalized OASPL is given as a function of impingement velocity for an EBF model with a 7-lobe mixer nozzle (high decay rate) and a model with a conical nozzle (low decay rate). The characteristics of the exhaust flow impingement profiles for these two nozzles and the corresponding impingement parameters were shown earlier in figure 5 . As shown in figure 5, the conical nozzle had one area of high velocity surrounding the peak impingement velocity, whereas the seven-lobed mixer nozzle had six high velocity areas which impinge on the flaps. The cross section of the mixer nozzle velocity profile at the 80 percent peak velocity location of each high velocity area was assumed to be circular in order to calculate the impingement area, $A_{i}$, for that nozzle. Thus for either type of nozzle the OASPL is simply dependent on the sixth power of the peak impingement velocity and on the first power of the impingement area, $A_{i}$.

\section{Flap Noise Field in Side-Line Plane}

Most of the flap noise data obtained were measured in the flyover plane. However, a limited amount of data were taken at other azimuthal angles. As shown in figure 2(b), the smal1 2-flap conical nozzle model could be rotated about the nozzle centerline axis in order to measure the flap noise field at various azimuthal angles. The results of this three-dimensional flap noise field survey were given in the form of directivity curves in reference 7 . In addition to the small model study a limited amount of noise data was taken with the large EBF models in the sideline plane. The data were taken at the wing-tip location $\left(\phi=0^{\circ}\right.$ in fig. 3(d)) with overhead boom microphones. The key results of the large scale tests will be discussed next.

Overa11 sound pressure level. - The OASPL measured at the wing-tip sideline microphone with the large two-flap model with the large two-flap model with a 13-in. diameter conical nozzle (非 of table I) is plotted against nozzle exhaust velocity in figure 12. The trailing flap angle was $60^{\circ}$. Data for the $85^{\circ}$ microphone (directly below the wing) are shown for comparison. The data show that the wing tip sideline noise level was approximately $10 \mathrm{~dB}$ quieter for this configuration at this flap angle. 
It was shown in the small model tests that the sideline noise reduction is smaller at lower flap deflection angles. Further, the change in noise level is dependent on both the polar angle $\theta$ and the azimuthal angle $\varphi$. Thus a considerable amount of additional three-dimensional mapping of the flap noise field will be needed in order to fully describe the directional characteristics.

Spectral shape. - Comparison of flyover and sideline noise spectra are complicated by the presence of ground reflection effects in the data. However, the limited test data obtained to date indicate that the measured sideline spectral shape is dependent on the polar and azimuthal angle of the microphone. Figure 13 compares the shape of the normalized sound pressure level (SPL-OASPL) one third-octave spectra at $90^{\circ}$ for a coaxial nozzle EBF configuration. The wing-tip sideline spectra is somewhat broader and therefore has more high frequency noise content. This effect is important in that the advantages of the lower OASPL at sideline positions tends to be partially negated by the effect of the high frequency noise on perceived noise level (PNdB).

\section{Flap Noise Suppression}

It was found early in the Lewis research program that flap interaction noise might be the dominant noise source for a powered lift aircraft having highly noise-suppressed engines. There are two broad approaches to solving the problem of suppressing flap noise. One method is to reduce the flap impingement velocity, and the other is to attempt to suppress the noise sources on (or adjacent to) the flap surfaces.

Reduction of impingement velocity. - The data of figures 10 and 11 show that the flap noise level is dependent on the sixth power of the peak flap impingement velocity and on the first power of the impingement area.

The flap impingement velocity for EBF systems employing turbofan engines can therefore be reduced by developing higher bypass ratio engines which have lower effective exhaust velocities. High-bypass-ratio engines have exhaust nozzles with a large total exit area (for the same thrust leve1). Because of the 6.7-power dependence on effective exhaust velocity in comparison with the first power dependence on exit area (fig. 9) the net effect should be to lower the flap noise level. Further, the increased nozzle diameter lowers the frequency (fig. 8) of the flap noise which in turn should have a beneficial effect on the perceived noise level.

The flap impingement velocity can also be reduced for a given engine cycle by employing a decayer type nozzle to reduce the peak velocity of the exhaust profile at the flap station (fig. 5). Among the high velocitydecay nozzles tested (see table $I$ ) was the large 7-lobe mixer nozzle (fig. 3(b)) discussed previously. The noise radiation pattern for this nozzle and the two-flap wing section (model 非) is compared in figure 14 
with data for the same wing-flap system blown by a conical nozzle. The trailing flap angle was $60^{\circ}$ (approach setting) and the nozzle exhaust velocity was $773 \mathrm{ft} / \mathrm{sec}$ for the data shown. For the mixer nozzle, because of the high decay rate, the peak impingement velocity at the flap station was only $487 \mathrm{ft} / \mathrm{sec}$. The mixer-nozzle-model OASPL (shown by the inner curve) is quieter at all angles than the conical nozzle configuration. For example, there is a 6-decibel suppression at $70^{\circ}$ from the inlet. This is about what would be expected from the data correlation of figure 11 if the reduction in peak impingement velocity, $v_{1, p}$, and the accompanying increase in $A_{i, p}$ associated with the mixer nozzle are taken into account.

Two problems are encountered with using mixer-decayer nozzles (refs. 22 to 24 and 27) to suppress flap noise. One is the rather large increase in $A_{i}$ that usually accompanies large reductions in $V_{i, p}$ 。 This partially cancels the benefits of reducing the impingement velocity. The other problem is related to the fact that mixer decayer nozzles usually have multiple flow passages (lobes, tubes, etc.). The small dimensions of these elements cause a considerable increase in the high frequency noise content of the nozzle-alone noise which when added to the reduced flap interaction noise results in a high-frequency floor for the spectra. This high frequency floor results in a rather high penalty in terms of the effect on perceived noise leve1. In addition, high-decayrate configurations can also adversely affect the thrust coefficient of the nozzle and the external drag during cruise.

The design of optimum mixer-decayer nozzles for flap noise reduction requires careful consideration of the trade offs involved with respect to acoustic and aerodynamic performance. Foremost is the determination of the proper velocity decay ratio $\left(V_{i, p} / V\right)$ for the desired reduction in flap noise. Excessive ratios generally are to be avoided because of the accompanying large jet spreading ratios which affect $A_{i}$. The second aspect is the design of the nozzle configuration (lobe number and shape) to produce the desired decay ratio with a minimum peak-frequency shift and with minimum aerodynamic losses. Implicit in such a design approach is the availability of adequate correlations of data for jet decay and. spreading rates for mixer nozzle configurations.

Source suppression. - Excellent discussions of the nature of the flap noise sources and various approaches to suppressing them are contained in references 20 and 41. Two of the methods suggested are acoustical treatment of the flap surfaces and trailing edge blowing. Details of these methods and results of small model tests are given by Hayden et al. In references 25 and 42 . Large-scale-model flap noise suppression tests were recently conducted at the Lewis Research Center to explore these methods further. These tests are summarized in table II along with some preliminary small scale tests. The large model cold-flow tests were conducted by modifying the flaps of the 7-foot chord two-flap model employing a 13-in. diameter conical nozzle ("\#3 of table I). The model with special flap sections installed is shown in figure 15. Figure 15(a) shows the model equipped for trailing edge blowing (\#3 of table II). The model equipped with porous skin leading and trailing edges (非 2 of table II) 
is shown in figure 15(b). The porous skin covered empty cavities divided into chambers by baffles. The research tests were conducted by the authors of reference 26 as a continuation and extension of the work described therein. Some typical preliminary results of the large model flap noise suppression tests are shown in figure 16. Results are shown for trailing edge blowing, covering the flap slots in the high impingement velocity region, porous surface treatment, and the use of screens to reduce the turbulence in the impinging flow. Typical noise suppressions (relative to normal hard surfaces), $\Delta \mathrm{dB}$, based on preliminary data measured in the forward quadrant $\left(\theta=0^{\circ}\right.$ to $\left.90^{\circ}\right)$ and in the rearward quadrant $\left(90^{\circ}\right.$ to $180^{\circ}$ ) below the wing are given in the figure.

The results indicate that some flap noise relief can be obtained by these methods provided the accompanying aerodynamic (1ift and drag) penalties are acceptable. In the case of trailing edge blowing the required air bleed flow rates from the turbofan engine must also be acceptable. Additional acoustic and aerodynamic research is clearly needed in order to fully evaluate the potential of these methods of suppressing flap noise.

\section{Re1ative Airspeed Effect Tests}

In addition to the static tests summarized in tables I and II tests were also conducted to determine the effects of relative airspeed (due to aircraft motion) on the nozzle exhaust plume characteristics and on the flap noise sources.

Effect on nozzle exhaust plume. - The exhaust-jet velocity decay and spreading characteristics of a variety of nozzle types were measured statically (ref. 21) and in the Lewis 6- by 9-foot wind tunnel in order to determine relative airspeed effects on the exhaust plume (refs. 43 and 44). Test results with and without the presence of tunnel airflow are given in figure 17 for both a high and a low velocity-decay type nozzle. The nozzles were an eight-tube mixer nozzle (shown in the photo) and a conical nozzle having nominal diameters of $2 \mathrm{in}$. The peak exhaust velocity decay ratio $V_{i, p} / V$ is plotted for each nozzle against normalized distance from the nozzle exit plane, $X / D_{T}$, for static conditions and for a tunnel airspeed of 100 knots. At $X / D_{T}$ values greater than 5 , the presence of tunnel airspeed had a considerable effect on the peak impingement velocity for the eight-tube nozzle. The effect on the low-decay conical nozzle was negliglble for $\mathrm{X} / \mathrm{D}_{\mathrm{T}}$ values less than about 8. Moderate-decay-rate mixer nozzles would fall somewhere in between these two cases. For EBF systems, $x / D_{T}$ distances from the nozzle exit plane to the flap impingement station are generally in the range of 5 to 12, with the 7 to 9 range being more typical. Figure 17 therefore shows that the effect of relative airspeed on the peak flap impingement velocity, $v_{i, p}$, must be taken into account - especially when mixer-decayer nozzles are employed. Changes in peak impingement velocity, of course, will result in changes in the flap noise level. 
Effect on flap noise. - Preliminary measurements of the effect of relative airspeed on flap noise were made using a 13-in. diameter free jet (ref. 30) to simulate airplane forward speed. A small-scale EBF model (非10 of table I) with a 2-in. diameter conical nozzle is shown mounted in the free-jet in figure 18. The wing support structure is outside the boundaries of the simulated airstream. Based on recent unpublished data correlations for this model, the following approximate relation holds in the flyover plane for the decrease in OASPL due to relative airspeed effects.

$$
\Delta(\text { OASPL })=k\langle\theta\rangle \log \left(\frac{\mathrm{V}-\mathrm{V}_{\mathrm{A}}}{\mathrm{V}}\right) \cdot \mathrm{dB}
$$

where $V$ is the nozzle exhaust velocity and $V_{A}$ is the forward velocity. The empirical parameter $k\langle\theta\rangle$ is a function of the flap deflection angle and the polar angle $\theta$. For polar angles between $\theta=20^{\circ}$ and $\theta=70^{\circ}$ in the forward quadrant below the wing the value of $\mathrm{k}\langle\theta\rangle$ was found to be equal to 6.0 for the test configuration of figure 18 when the trailing flap was in the $60^{\circ}$ position. When the trailing flap was in the $20^{\circ}$ position the value of $k\langle\theta\rangle$ was found to be equal to 35.0 for polar angles between $\theta=20^{\circ}$ and $120^{\circ}$.

Effect of aircraft motion on flap noise. - In order to obtain preliminary estimates of aircraft motion effects on the flap noise, the effect of relative motion of the noise source with respect to the observer must be added to the relative airspeed effect measured in the free jet. Reference 45 gives the relative motion effects for a point dipole noise source. Assuming that as a rough approximation the flap noise field can be treated as if it were radiating from a point dipole on the trailing flap, then the convective (or Doppler) amplification is given by

$$
\Delta(\text { OASPL })=-40 \log \left[1-\left(\frac{V_{A}}{C_{0}}\right) \cos \theta\right] \quad d B
$$

and the Doppler effect on the frequency is given by

$$
\mathrm{f}_{F V}=\frac{\mathrm{f}_{\mathrm{c}}}{1-\left(\frac{\mathrm{V}_{\mathrm{A}}}{\mathrm{C}_{\mathrm{o}}}\right) \cos \theta}
$$

where $C_{0}$ is the ambient speed of sound.

The two effects of afrcraft motion can be combined into a single expression to represent the net effect on flap noise. For example, the OASPL for an EBF system with a conical nozzle is given by 


$$
\mathrm{OASPL}_{\mathrm{FV}}=\mathrm{OASPL}_{\theta}-40 \log \left[1-\left(\frac{\mathrm{V}_{\mathrm{A}}}{\mathrm{C}_{\mathrm{o}}}\right) \cos \theta\right]+\mathrm{k}\langle\theta\rangle \log \left(\frac{\mathrm{V}-\mathrm{V}_{\mathrm{A}}}{\mathrm{V}}\right)
$$

and the frequency shift is given by equation (8).

As a simple illustration of the expected effect of aircraft motion on the flap noise level consider two examples. The first case is for an approach flap setting of $60^{\circ}, \theta=70^{\circ}, V_{A}=120 \mathrm{ft} / \mathrm{sec}, V=500 \mathrm{ft} / \mathrm{sec}$, and $C_{0}=1050 \mathrm{ft} / \mathrm{sec}$. From equation (9), OASPL $\mathrm{FV}=0 \mathrm{OSPL} 700+0 \mathrm{~dB}$. Thus, in this case the two effects of aircraft motion on the noise level cancel each other out.

The second case is for a takeoff trailing flap setting of $20^{\circ}$, $\theta=100^{\circ}, V_{A}=150 \mathrm{ft} / \mathrm{sec}, V=700 \mathrm{ft} / \mathrm{sec}$, and $C_{o}$ is the same as for the first example. From equation (9)

$$
\mathrm{OASPL}_{\mathrm{FV}}=\mathrm{OASPL}_{100^{\circ}}-4.1 \mathrm{~dB}
$$

For this case the two effects of aircraft motion are additive resulting in a significant decrease in noise in the $\theta=100^{\circ}$ direction.

Further experiments are needed to determine the sensitivity of $k\langle\theta\rangle$ to EBF configuration differences and ultimately, of course, these preliminary trends will have to be checked against noise measured during an actual aircraft flyover.

\section{ENGINE OVER THE WING RESULTS}

In contrast to the UTW case, flap noise test results were obtained with only one large-scale OTW EBF model. This model was a conical nozzle with a flow deflector configuration. These results along with the results from the sma1l model OTW configuration screening tests will be discussed in this section.

\section{Flap Noise Field in Flyover Plane}

Noise radiation pattern. - Typical flap noise radiation patterns at 50 foot radius for the large OTW model are shown in figure 19 (taken from ref. 33). The OASPL is given as a function of the angle from the inlet in the flyover plane (fig. 3(d)). The data were obtained with model 1 17 of table I which was a 7-foot chord 2-flap mode1 with a 13-in. contcal nozzle and flow deflector (fig. 3(c)). The flap slots were covered. Data are shown for four nozzle exhaust velocities between 680 and $945 \mathrm{ft} / \mathrm{sec}$ and for two flap settings. Data taken with the trailing flap at $20^{\circ}$ are shown in figure 19 (a) and data for the $60^{\circ}$ position are given in 19(b). Because of wing shielding the noise levels below the wing are generally considerably less than those measured above the wing. In addi- 
tion, the OASPL below the wing is nearly constant with angle over a considerable range of polar angles. In contrast to the radiation patterns for the large UTW model previously shown in figure 6, comparison of the data in figures $19(\mathrm{a})$ and (b) show that there was only a small change in noise level with flap deflection angle.

Flap noise spectra. - The effects of wing shielding can be better understood by examining the noise spectra. They show that although a considerable amount of additional noise is generated by the attached flow over the wing and flaps, much of this noise is shielded by the wing from observers located below the EBF model. The amount of noise generated by the attached flow can be seen by examining the power spectra. Sound power spectral plots are shown in figure 20 for two small-model OTW configurations. The models had a circular nozzle with an exhaust-jet flow deflector and a 10:1 slot nozzle canted towards the wing and flap system to promote flow attachment. The sound power level plotted is that obtained from acoustic measurements in the flyover plane. Because tests have indicated only a small azimuthal variation in noise, the sound power levels shown approximate the true power spectra. The sound power spectra for the configurations shown are independent of any noise intensity reduction caused by shielding or reflection; consequently, they represent the total noise generated and radiated at all polar angles (both above and below the wing).

In figure 20(a), typical sound power spectra for a configuration having a deflector are shown. These spectral plots shown are for the circular nozzle alone, the nozzle with deflector, and finally the nozzle with deflector and wing. It is apparent that the interaction between the jet and the deflector causes a large increase in noise. This increase in noise is similar to that associated with lower surface blowing on a flap. The addition of the wing causes another increase in noise but only at lower frequencies. This latter increase in noise is presently attributed to two primary factors: (1) scrubbing of the attached jet flow over the wing surface and (2) flap trailing edge noise (ref. 17).

A typical sound power spectral plot for the canted 10:1 slot nozzle with and without a wing is shown in figure $20(\mathrm{~b})$. It is apparent that the increase in noise level with the wing in place occurs primarily at low and middle frequencies. This increase in noise is again attributed to the jet flow scrubbing over the wing surface and the noise generated at the flap trailing edge. It should be noted that again the presence of the wing contributes substantially no increase in sound power level at high frequencies. This can become significant in terms of the effect on perceived noise level when sma11-scale data are scaled to full-sized aircraft.

As noted in figure 19 much of the noise generated by the attached flow over the wing and flap system is shielded from observers located below the wing. This effect is clearly shown by the large OTW model data of figure 21 (taken from ref. 30). Typical noise spectra at 50 feet and $90^{\circ}$ from the inlet are shown. The flaps were in the $30^{\circ}-60^{\circ}$ position 
and the slots were covered. The nozzle exhaust velocity was $680 \mathrm{ft} / \mathrm{sec}$. The data are for the nozzle alone, nozzle and deflector, and nozzle plus deflector and wing. As noted in the power spectra of figure 20(a) there is a large increase in noise when the flow deflector is added to the nozzle. When the nozzle plus deflector is placed above the wing much of the high frequency noise is shielded from the $90^{\circ}$ microphone by the wing. Further, when the exhaust flow is attached to the flap system, figure 21 shows that there is a large increase in low-frequency trailing edge noise below the wing.

Normalized one third octave sound pressure level spectra (SPL-OASPL) are shown in figure 22 for the large OTW model as a function of the Strouhal number ( $f D / V$ ) based on nozzle diameter, $D$, and nozzle exhaust velocity, $V$. The spectra were corrected for ground reflections. The trailing flap angle was $20^{\circ}$ and the microphone angle was $100^{\circ}$. The curves shown were drawn through eight sets of data points for velocities between 550 and $1000 \mathrm{ft} / \mathrm{sec}$. Spectra are shown for the $100^{\circ}$ microphone in the flyover plane and for the wingtip sideline position $\left(\phi=0^{\circ}\right.$ in sideline plane of figure 3(d)). The flyover plane spectra is double peaked. The peak occurring at a strouhal number of about 0.36 appears to be caused by the deflector noise while the peak occurring at 0.09 is probably caused by the trailing edge noise. The wingtip sideline spectrum will be discussed later.

OTW flap nolse scaling. - The large-model flyover plane spectral data of figure 22 is shown in the form of normalized SPL spectral density $(S P L-O A S P L+10 \log$ V/D $\Delta f$ ) plotted against Strouhal number in figure 23 (taken from ref. 33). Also shown is a curve obtained from a similar correlation for a small scale model of the same configuration (非18 of table I). At this microphone angle $\left(100^{\circ}\right)$, the small and large scale data are correlated quite well by the parameters of figure 23 .

The OTW data, however, do not scale as well at all angles. This is illustrated in figure 24 (from ref. 33) where the OASPL for the same models is compared at all angles in the flyover plane. The small model data were scaled up to the large model data using the scaling relation given in equation (5) (see ref. 33 for details). Figure 24 shows that the scaling laws work well in a limited angular region directly below the wing. Conversely they work poorly for polar angles directly above the wing. The differences appear to be due to poor scaling results for the flow deflector noise. This problem was not encountered when scaling the UTW small scale model results up to large model results (see ref. 14). This point needs to be investigated further. In addition, the scaling laws for other OTW systems such as the slot nozzle configuration must be determined.

Variation of noise level with velocity. - As in the UTW case the flap noise level is dependent on nozzle exhaust velocity. This effect is shown in figure 25 (taken from ref. 33). The results are for the large OTW model (非7) and are given for three flap positions. Figure 25(a) shows that the OASPL at $90^{\circ}$ from the inlet varies as the sixth power of 
the nozzle exhaust velocity (eq. (5)). Further the data for the trailing flap position of $20^{\circ}$ is nearly the same as for the $60^{\circ}$ position. The data for the flaps retracted case show that the noise is increased below the wing, in comparison to the deflected-flap cases, because the wing is not as large a shield with the flaps retracted (compared to flaps extended with slots covered).

The percelved noise level at 500 feet from the model for the microphone yielding the flyover maximum is given for the same test conditions in figure $25(\mathrm{~b})$. In terms of $\mathrm{PNL}$ the $10^{\circ}-20^{\circ}$ position is the quietest of the three flap positions. The differences however are small in terms of PNdB.

\section{Flap Noise Field in Side-LIne Plane}

In addition to the flyover measurements, noise data were also taken for the OTW EBF models at various sideline locations as indicated in figure $3(d)$.

Flap noise data for the large OTW model (非17) measured at three microphone locations in the $100^{\circ}$ sideline plane are shown in figure 26 (from ref. 33). The one-third-octave-band SPL spectra measured at $50 \mathrm{ft}$ are shown in figure 26(a). The spectra were not corrected for ground effects so strong reinforcements and cancellations affect the low frequency part of the spectra. However, it can be seen that the wingtip sideline microphone $\left(0^{\circ}\right)$ has more high frequency noise and less low frequency noise than the microphone in the flyover plane $\left(90^{\circ}\right)$.

This change in shape is more clearly seen when the data are corrected for ground effects as was shown in the normalized spectra of figure 22. Figure 22 shows that the wingtip sideline spectra has a single peak in contrast to the double-peaked curve for the flyover plane. Further, it clearly has more high frequency noise content. The shape of the wingtip sideline spectra is apparently controlled primarily by the nozzle-plus-deflector noise which is not shielded by the wing at this microphone location.

The spectra for the $27^{\circ}$ location in the flyover plane shows the least high frequency noise (fig. 26(a)). This results in a low perceived noise level at this location as can be seen from the results shown in figure 26(b). In figure 26(b) the perceived noise level at $500 \mathrm{ft}$ from the model is plotted against nozzle exhaust velocity. The PNL's for the wingtip sideline and flyover microphones are very nearly the same although the spectra are different. This occurs because the PNL calculation weights the high frequency SPL's more than the low frequency values.

Effect of Nozzle Configuration on Flap Noise

The results of the noise screening tests for the small oTW models of 
table I were summarized in reference 31 . For models having good exhaust flow attachment to the flap system it was found that for polar angles directly below the wing $\left(70^{\circ}\right.$ to $120^{\circ}$ ) the flap noise was only moderately sensitive to the type of nozzle employed (circular, 8-1obe mixer, slot, "D" shaped, etc.). This effect was caused in part by the fact that the wing shielded much of the middle and high frequency noise from this region below the wing. Data for the 10 to 1 slot nozzle configuration (model \#24) was the quietest of the OTW EBF systems tested when all other parameters were held constant. However, it was only a little quieter than the circular nozzle with deflector configuration. For example, at $120^{\circ}$ from the inlet and with the flaps at the $20^{\circ}$ trailing flap position, it was only 2 to $3 \mathrm{~dB}$ quieter over most of the SPL spectrum.

To illustrate this point, spectral data for two types of OTW EBF configurations under consideration are compared in figure 27 (from ref. 3I). In figure 27 the one-third octave SPL spectra for the small circular nozzle with deflector model and the small 2 to 1 aspect ratio "D" nozzle with deflector model are compared at three nozzle exhaust velocities. The data show that the differences in the spectra are smal1. Thus the choice between these two nozzles would more likely depend on aerodynamic, structural, and operational considerations rather than on any advantages from the standpoint of noise.

\section{Effect of Flow Attachment Devices on Flap Noise}

Small model tests were also run to determine the effect of various types of flow attachment methods on the noise spectra below the wing. Nozzles were employed with no device, with side plates, with flow deflectors, and with the nozzles canted downward towards the wing to promote attachment.

In figure 28 (from ref. 31) the one-third-octave band SPL spectra for the cylindrical nozzle model with different attachment schemes are compared. With no device attachment did not occur and the spectrum is only a little louder at low frequencies and is quieter at high frequencies (because of shielding) than the nozzle alone spectrum. By canting the nozzle or using a flow deflector good attachment was achieved. The data for these two cases are very similar at all frequencies. Note the strong increase in low and middle frequency noise in both cases when the flow is attached to achieve powered lift.

Similar spectral comparisons are made in figure 29 (from ref. 31) for the slot nozzle EBF configurations with various attachment devices. The 5 to 1 slot nozzle model results are compared in figure 29 (a) and the 10 to 1 slot nozzle results are given in figure 29(b). For both tests, the trailing flap was at $20^{\circ}$ and the nozzle exhaust velocity was $750 \mathrm{ft} / \mathrm{sec}$. The microphone angle was $120^{\circ}$. Figure 29 shows that with attached flow, the spectra for both nozzles were nearly independent of the scheme used. As noted in the previous figure, when there was substantially no flow attachment (5 to 1 slot nozzle with no device), the 
spectra were considerably different in that there was much less low frequency noise.

Thus the method or device used to obtain flow attachment to the wing and flap system had only secondary effects on the flap noise and had little effect on the jet noise shielding characteristics of the system.

\section{COMPARISON OF OTW AND UTW MODEL RESULTS}

The OTW EBF noise data for the large mode1 are compared in figure 30 (taken from ref. 33) with similar data from the large UTW EBF model. Both models (\#17 and 非 3 of table I) used the same seven-foot chord wing section and 13-in. diameter conical nozzle. The OTW model had a flow deflector. Figure 30 compares the 500-ft perceived nolse levels for the two models at two test conditions. Data with the trailing flap at $20^{\circ}$ and a nozzle exhaust velocity of $765 \mathrm{ft} / \mathrm{sec}$ are given in figure $30(\mathrm{a})$. Figure $30(\mathrm{~b})$ gives the data for the $60^{\circ}$ flap and an exhaust velocity of $680 \mathrm{ft} / \mathrm{sec}$. The data of figure 30 show that because of wing shielding the OTW nodel is clearly quieter below the wing. At $90^{\circ}$ the OTW model is more than $10 \mathrm{PNdB}$ quieter with the flaps at the $20^{\circ}$ trailing angle setting and about 9 PNdB quieter with the flaps at the $60^{\circ}$ position.

The perceived nolse level at 500 feet from the same two models is compared as a function of nozzle exhaust velocity in figure 31 (from ref. 33) for two different flap angles. The microphone angles in each case are those (approximately) which yield the maximum noise at f1yover. At both trailing flap angles the OTW model is about 10 PNdB quieter over the velocity range shown. The PNAB curves are nearly parallel indicating that both models have a similar PNL dependence on exhaust velocity.

\section{CONCLUDING REMARKS}

The results of the Lewis Research Center cold-flow model flap noise tests of UTW and OTW EBF systems have been summarized and key conclusions have been discussed.

With the UTW system the sources of the flap noise are well enough understood to permit accurate correlation of the data in terms of exhaust flow flap impingement parameters. The use of impingement parameters permits correlation of the overall sound pressure level data for a variety of EBF configurations having both high and low exhaust-velocity-decay nozzles. Further, flap noise scaling laws have been devised which permit accurate prediction of the flap noise for linearly scaled up versions of the test models. The three-dimensional flap noise field has been tentatively defined; however, more data are needed to accurately define the noise field at all angles. Further work is also needed to determine the effect of major departures from the EBF configurations tested such as the effect of employing high-area-ratio coaxial nozzles to simulate very high bypass ratio turbofan engine exhaust nozzles. 
The OTW flap noise sources are not as well understood at this point. However, the OASPL data correlate quite well in terms of nozzle exit flow parameters. Further, considerable data has been obtained on the wing shielding effects. Because of wing shielding the flap noise directly below the wing is not as loud as measured with the UTW system. Flap noise scaling laws have been devised which work reasonably well in the shielded region below the wing. However, at other angles the scaling laws do not work well. In order to devise better scaling laws, and to better determine configuration effects, additional large model noise test data are needed.

For both the OTW and UTW EBF systems further tests of noise suppression methods and forward velocity effects are needed as only limited preliminary data are available in these areas.

In summary, the cold-flow model program has defined the general characteristics of both the OTW and UTW flap noise fields. These results in turn have guided the Lewis full-scale engine flap noise programs and have permitted the development of preliminary flap noise prediction methods.

\section{REFERENCES}

1. John P. Campbell and Joseph $\mathrm{L}_{0}$ Johnson, Jr。, "Wind-Tunnel Investigation of an External-Flow Jet-Augmented Slotted Flap Sultable for Application to Airplanes With Pod-Mounted Jet Engines." NACA TN-3898, December 1956.

2. John G. Lowry, John M. Riebe, and John P. Campbe11, "The Jet-Augmented Flap," Preprint no. 715, Institute of Aeronautical Sciences, January 1957.

3. Thomas Ro Turner, Edwin E。 Davenport, and John M. Riebe, "Low-Speed Investigation of Blowing From Nacelles Mounted Inboard and on the Upper Surface of an Aspect-Ratio-7.0 $35^{\circ}$ Swept Wing with Fuselage and Various Tall Arrangement." NASA MEMO 5-1-59L, June 1959.

4. Domenic J. Magieri, and Harvey H. Hubbard, "Preliminary Measurements of the Noise Characteristics of Some Jet-Augmented-Flap Configurations." NASA MEMO 12-4-58L, 1959.

5. R. G. Dorsch, E。 A. Krejsa, and W. A. 01sen, "Blown Flap Noise Research," AIAA paper no. 71-745, Propulsion Joint Specialist Conference, 7 th, Salt Lake Ctty, June 1971.

6. R. G. Dorsch, W. J. Kreim, and W. A. O1sen, "Externally-Blown-Flap Noise," AIAA paper no. 72-129, Aerospace Sciences Meeting, 10th, San Diego, January 1972.

7. William A。 Olsen, Robert G。 Dorsch, and Jeffrey H. Miles, "Noise Produced by a Smal1-Scale Externally Blown Flap." NASA TN D-6636, March 1972. 
8. Frederick W. Gibson, "Noise Measurements of Model Jet-Augmented Lift Systems." NASA TN D-6710, April 1972.

9. T. W. Putnam, and P. L。 Lasagna, "Externally Blown Flap Impingement Noise," AIAA paper no. 72-664, Fluid and Plasma Dynamics Conference, 5th, Boston, June 1972 .

10. Michael D. Falarski, Kiyoshi Aoyagi, and David G. Koenig, "Acoustic Characteristics of Large-Scale STOL Models at Forward Speed." NASA SP-320, October 1972, pp. 443-448.

11. Paul L. Lasagna and Terrill W. Putnam, "Externally Blown Flap Impingement Noise." NASA SP-320, October 1972, Pp. 427-433.

12. W. L. Jones, L. J. Heidelberg, and R. G. Goldman, "Highly Noise Suppressed Bypass 6 Engine for STOL Applications," AIAA paper no. 731031, Aero-Acoustics Conference, Seattle, Octaber 1973.

13. N. E. Samanich, L. J. Heidelberg, and W. L. Jones, "Effect of Exhaust Nozzle Configuration on Aerodynamic and Acoustic Performance of an Externally Blown Flap System with a Quiet 6:1 Bypass Ratio Engine," AIAA paper no. 73-1217, Propulsion Conference, 9th, Las Vegas, November 1973.

14. Robert G. Dorsch, Paul L. Lasagna, Domenic J. Maglieri, and William A. O1sen, "Flap Noise." NASA SP-311, May 1972, pp. 259-290.

15. William A. OIsen, Jeffrey H. Miles, and Richard G. Dorsch, "Noise Generated by Impingement of a Jet Upon a Large Flat Board." NASA TN D-7075, December 1972.

16. R. G. Dorsch, J. H. Goodykoontz, and N. B. Sargent, "Effect of Configuration Variation on Externally Blown Flap Noise," AIAA paper no. 74-190, Aerospace Sciences Meeting, 12th, Washington, JanuaryFebruary 1974。

17. R. E. Hayden, "Noise from Interaction of Flow with Rigid Surfaces: A Review of Current Status of Prediction Techniques." NASA CR-2126, October 1972 .

18. B. Clark, R. Dorsch, and M. Reshotko, "Flap Noise Prediction Method for a Powered Lift System," AIAA paper no. 73-1028, Aero-Acoustics Conference, Seattle, October 1973.

19. J. H. Miles, "Rational Function Representation of Flap Noise Spectra Including Correction for the Reflection Effects," AIAA paper no. 74-193, Aerospace Sclences Meeting, 12th, Washington, JanuaryFebruary 1974。

20. David Chestnutt, Domenic J. Maglieri, and Richard E。 Hayden, "Flap Noise Generation and Contro1." NASA SP-320, October 1972, pp. 413-419. 
21. U. H. von Glahn, D. E. Groesbeck, and R。 G. Huff, "Peak Axial-Velocity Decay with Single- and Multi-Element Nozzles," AIAA paper no. 72-48, Aerospece Sciences Meeting, 10th, San Diego, January 1972 .

22. J. H. Goodykoontz, W. A. 01sen, and R. G. Dorsch, "Sma11-Scale Tests of the Mixer Nozzle Concept for Reducing Blown-Flap Noise." NASA TM X2638, November 1972。

23. Jack H. Goodykoontz, Robert G. Dorsch, and Donald E. Groesbeck, "Noise Tests for a Mixer Nozzle - Externally Blown Flap System." NASA TN D-7236, May 1973.

24. J. H. Goodykoontz, R. G. Dorsch, and J. M. Wagner, "Acoustic CharacterIstics of Externally Blown Flap Systems with Mfxer Nozzles," AIAA paper no. 74-192, Aerospace Sciences Meeting, 12th, Washington, January-February 1974.

25. R。 E. Hayden, T. D. Scharton, Y. Kadman, J。 Wilby, and Mo J. Rud, "A Preliminary Evaluation of Noise Reduction Potential for the Upper Surface Blown Flap," BBN-2478, Bolt, Beranek, and Newman, Inc。 (NASA CR-112246), 1972。

26. D. J. McK1nzie, Jr., and R. J. Burns, "Externally Blown Flap Trailing Edge Noise Reduction by Slot Blowing - A Preliminary Study," AIAA paper no. 73-245, Aerospace Sciences Meeting, 11th, Washington, January 1973.

27. Jack H. Goodykoontz, Jack M. Wagner, and Noel B. Sargent, "Noise Measurements for Various Configurations of a Model of a Mixer Nozzle Externally Blown Flap System." NASA TM X-2776, April 1973.

28. Mo Reshotko, W. A。 Olsen, and R。 Go Dorsch, "Preliminary Noise Tests of the Engine-Over-the-Wing Concept. Io $30^{\circ}-60^{\circ}$ Flap Position." NASA TM X-68032, 1972 .

29. Meyer Reshotko, William A. Olsen, and Robert G。 Dorsch, "Preliminary Noise Tests of the Engine-Over-the-Wing Concept. II。 $10^{\circ}-20^{\circ}$ Flap Position." NASA TM X-68104, 1972.

30. Robert G. Dorsch, and Meyer Reshotko, "EBF NoIse Tests with Englne Under-the-Wing and Over-the-Wing Configurations." NASA SP-320, October 1972, pp. 455-473.

31. R。 G. Dorsch, M。 Reshotko, and W. A. O1sen, "Flap Noise Measurements for STOL Configurations Using External Upper Surface Blowing," ATAA paper no. 72-1203, Joint Propulsion Specialist Conference, 8th, New Orleans, November-December 1972。

32. U, von Glahn, M. Reshotko, and R. Dorsch, "Acoustic Results Obtained with Upper-Surface-Blowing Lift-Augmentation Systems." NASA TM X68159, November-December 1972 . 
33. M. Reshotko, J。 H. Goodykoontz, and R。 G。 Dorsch, "Engine-Over-the-Wing Noise Research," AIAA paper no. 73-631, Fluid and Plasma Dynamics Conference, 6th, Palm Springs, July 1973.

34. M. D. Falarsk1, K. Aoyagi, and D. G. Koenig, "Acoustic Characteristics of a Large-Scale Wind-Tunnel Mode1 of an Upper-Surface Blown Flap Transport Having Two Engines." NASA TM X-62319, September 1973.

35. M. Reshotko, and R. Friedman, "Acoustic Investigation of the EngineOver-the-Wing Concept Using a D-Shaped Nozzle," AIAA paper no. 73-1030, Aero-Acoustics Conference, Seattle, October 1973.

36. W11liam A. Olsen, and Robert Friedman, "Noise Tests of a Model EngineOver-the-Wing STOL Configuration Using a Multijet Nozzle with Deflector." NASA TM X-2871, August 1973.

37. Allen M. Karchmer, and Robert Friedman, "Noise Tests of an Externally Blown Flap with the Engine in Front of the Wing." NASA TM X-2942, December 1973.

38. W. J. Jones, L. J. Heidelberg, and R. G. Goldman, "Highly NolseSuppressed Bypass 6 Engine for STOL Applications," AIAA paper no. 73-1031, Aero-Acoustics Conference, Seattle, October 1973.

39. N. E. Samanich, L. J. Heidelberg, and W. L. Jones, "Effect of Exhaust Nozzle Configuration of Aerodynamic and Acoustic Performance of an Externally Blown Flap System with a Quiet 6:1 Bypass Ratio Engine," AIAA paper no. 73-1217, Propulsion Conference, 9th Las Vegas, November 1973.

40. W. L. Jones, and L. J. Heldelberg, "Investigation of Noise from Ful1Scale High By-Pass Engine and Blown Flap System," SAE paper 740467, Atr Transportation Meeting, Dallas, May 1974.

41. R。 E. Hayden, "Fundamental Aspects of Noise Reduction from PoweredLift Devices," SAE paper 730376, Air Transportation Meeting, Miami, Apri1 1973.

42. Richard E. Hayden, Yoram Kadman, and Robert C. Chanaud, "A Study of the Variable Impedance Surface Concept as a Means for Reducing Noise from Jet Interaction with Developed Lift-Augmenting Flaps," Rept. 2399, Bolt, Beranek, and Newman, Inc. (NASA CR-112166), July 1972.

43. U. von Glahn, N. Sekas, and D. Groesbeck, "Forward F1Ight Effects on Mixer Nozzle Design and Noise Considerations for STOL Externally Blown Flap Systems," AIAA paper no. 72-792, Aircraft Design, Flight Test, and Operations Meeting, 4th, Los Angeles, August 1972. 
44. U. von Glahn, D. Groesbeck, and Jo Goodykoontz, "Velocity Decay and Acoustic Characteristics of Various Nozzle Geometries with Forward Velocity," AIAA paper no.73-629, Fluid and Plasma Dynamics Conference, 6th, Palm Springs, July 1973.

45. M. J. Lighthill, "The Bakerian Lecture, 1961 - Sound Generated Aerodynamically." Proc. Roy. Soc. (London), Vo1. A267, 1962, pp. 147-182. 
TABLE I. - SUMMARY OF LEWIS COLD FLOW EBF MODEL ACOUSTIC TESTS

A. UTW-EBF MODELS

\begin{tabular}{|c|c|c|c|c|}
\hline $\begin{array}{l}\text { Model } \\
\text { no. }\end{array}$ & Nozzle type & $\begin{array}{l}\text { Number } \\
\text { of flaps }\end{array}$ & $\begin{array}{l}\text { Trailing } \\
\text { flap angles } \\
\text { tested, } \\
\text { deg }\end{array}$ & $\begin{array}{l}\text { Ref. } \\
\text { no. }\end{array}$ \\
\hline
\end{tabular}

I. Large Model (7-ft Chord Wing Section)

(a) Conventional (Low-Velocity-Decay) Exhaust Nozzles

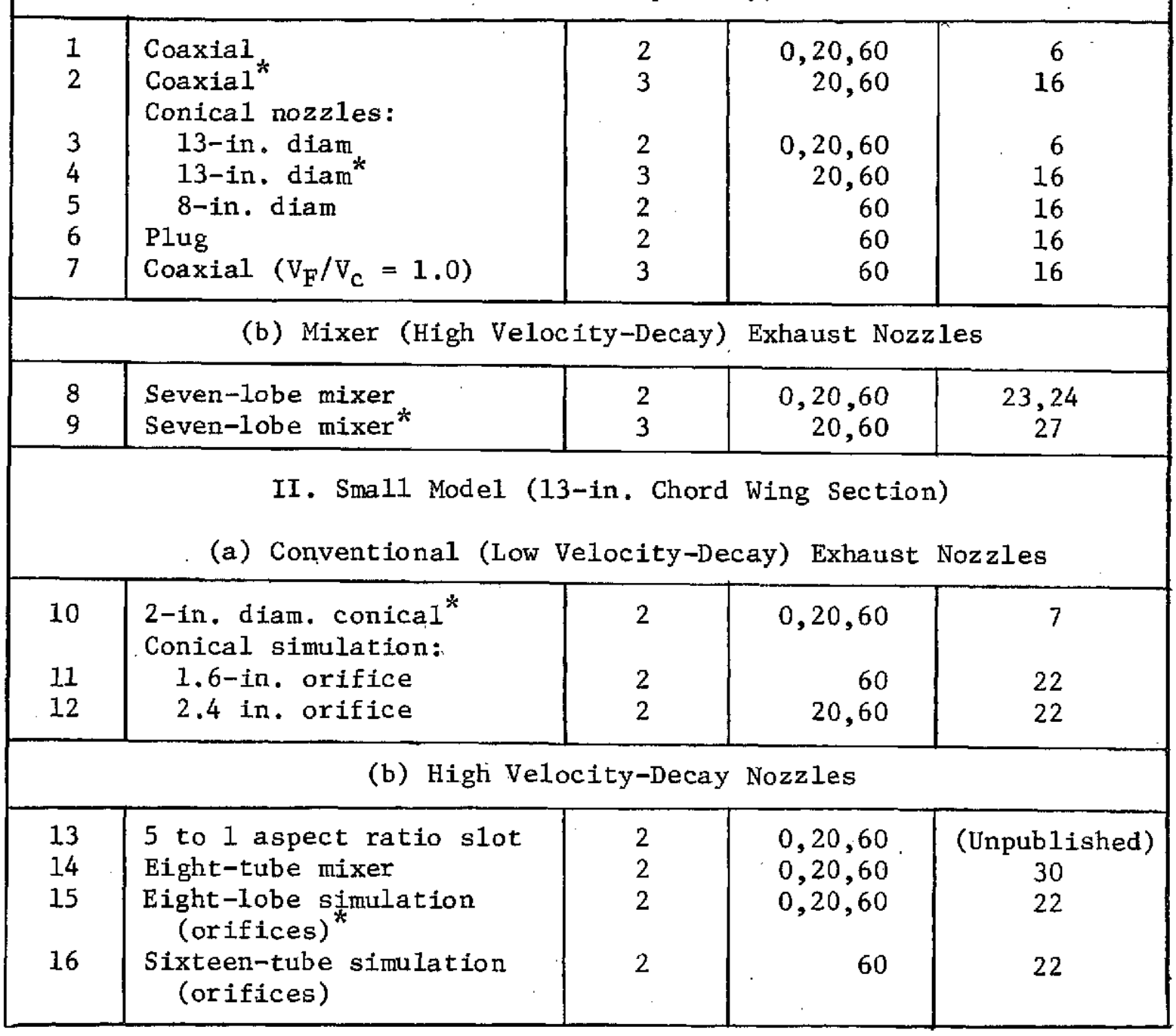


TABLE I. - Concluded. SUMMARY OF LEWIS COLD-FLOW

EBF MODEL ACOUSTIC TESTS

B. OTW-EBF MODELS

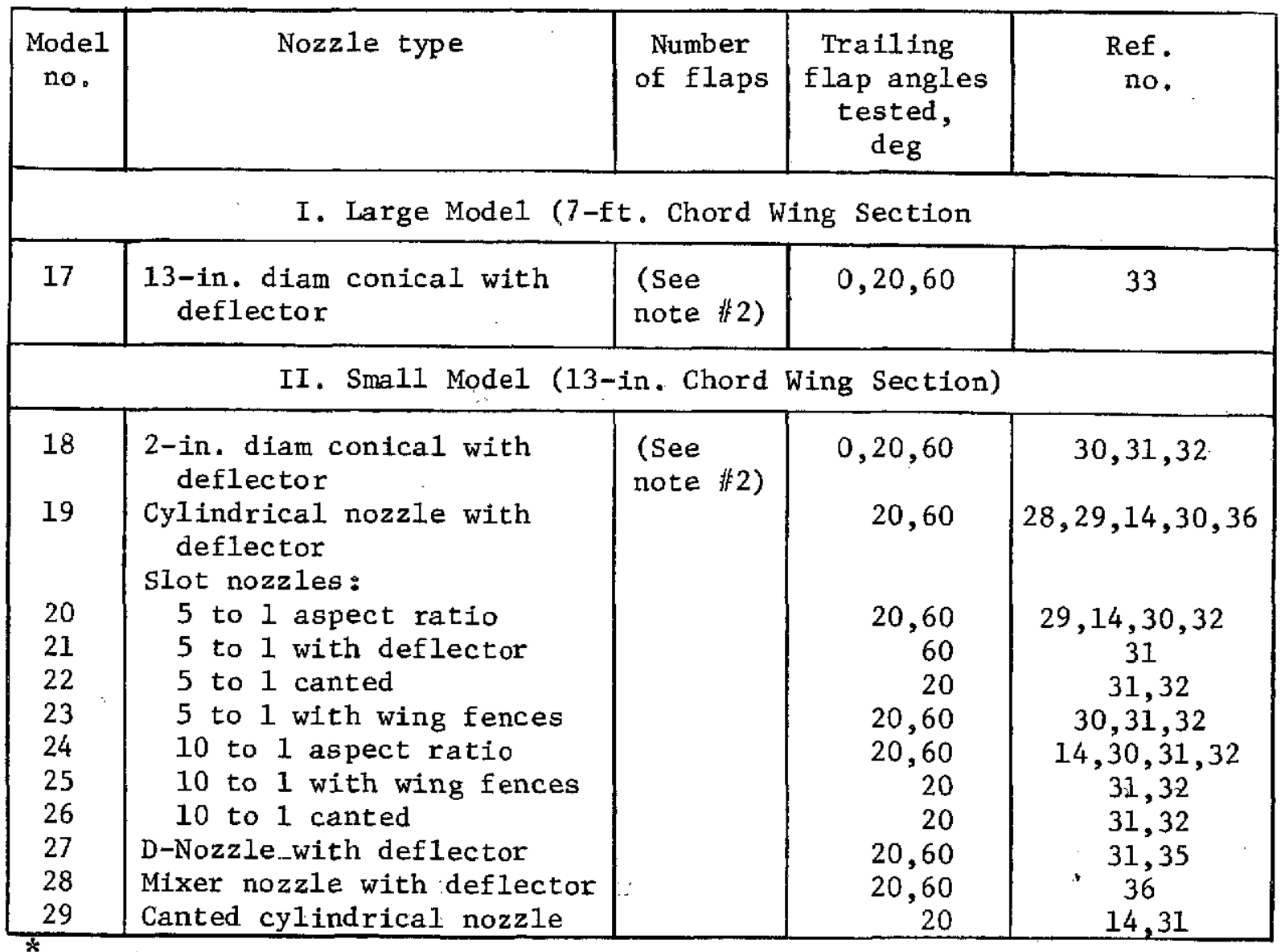

Note 非: Nozzle tested in more than one position.

Note 非: Two-flap wing with slots covered. Some tests were also run with slots open. 
TABLE II. - SUMMARY OF LEWIS COLD-FLOW EBF

MODEL FLAP NOISE SUPPRESSION TESTS

\begin{tabular}{|c|c|c|c|c|}
\hline $\begin{array}{l}\text { Mode1 } \\
\text { no. }\end{array}$ & Nozzle type & Flap geometry & Suppression devices & Ref. \\
\hline \multicolumn{5}{|c|}{ A. Large Model (7-ft Chord, 9-ft Span) } \\
\hline 1 & $\begin{array}{l}\text { 13-in. diam } \\
\text { conical }\end{array}$ & $\begin{array}{l}\text { Two-flaps, } \\
60^{\circ} \text { trailing } \\
\text { flap }\end{array}$ & $\begin{array}{l}\text { Screens over flap } \\
\text { surfaces and slots }\end{array}$ & $\begin{array}{l}\text { Recent } \\
\text { unpub1. }\end{array}$ \\
\hline 2 & Same & Same & $\begin{array}{l}\text { Porous leading and } \\
\text { trailing edges on } \\
\text { flaps }\end{array}$ & $\begin{array}{l}\text { Recent } \\
\text { unpub1. }\end{array}$ \\
\hline 3 & Same & Same & $\begin{array}{l}\text { Trailing edge blow- } \\
\text { ing from flaps }\end{array}$ & $\begin{array}{l}\text { Recent } \\
\text { unpubl. }\end{array}$ \\
\hline 4 & Same & Same & $\begin{array}{l}\text { Slots between flaps } \\
\text { covered locally }\end{array}$ & $\begin{array}{l}\text { Recent } \\
\text { unpub1. }\end{array}$ \\
\hline \multicolumn{5}{|c|}{ B. Sma11 Model (Wing Model, 13-in. Chord) } \\
\hline 5 & $\begin{array}{l}2-i n . \text { diam } \\
\text { circular convergent }\end{array}$ & $\begin{array}{l}\text { Two-flaps, } \\
60^{\circ} \text { trailing } \\
\text { flap }\end{array}$ & $\begin{array}{l}\text { Screens over flap } \\
\text { surfaces and slots }\end{array}$ & Unpub1. \\
\hline 6 & Same & $\begin{array}{l}\text { Flat plate at } \\
60^{\circ} \text { with im- } \\
\text { pact zone near } \\
\text { trailing edge }\end{array}$ & $\begin{array}{l}\text { Screens over plate } \\
\text { surfaces }\end{array}$ & Unpub1. \\
\hline 7 & Same & Same & $\begin{array}{l}\text { Blowing from slots } \\
\text { in vicinity of and at } \\
\text { the trailing edge }\end{array}$ & 26 \\
\hline
\end{tabular}




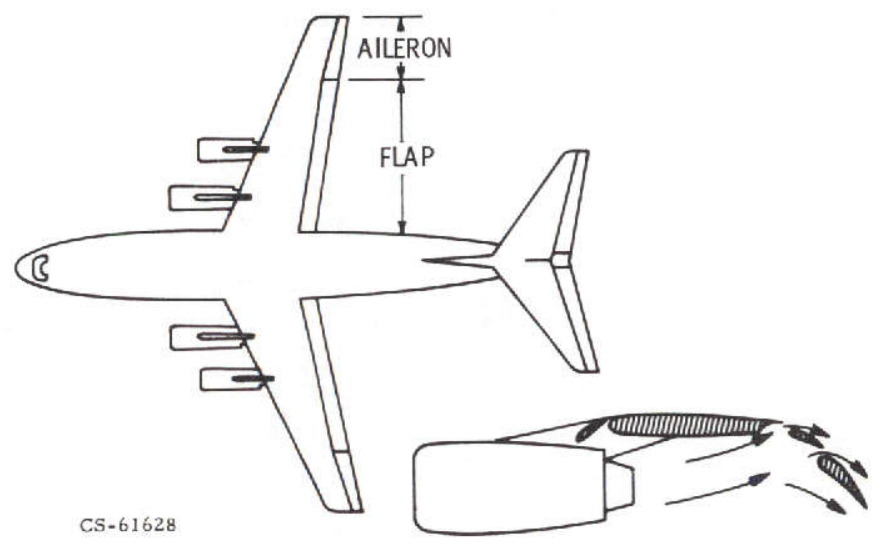

(a) ENGINE-UNDER-THE-WING CONCEPT.

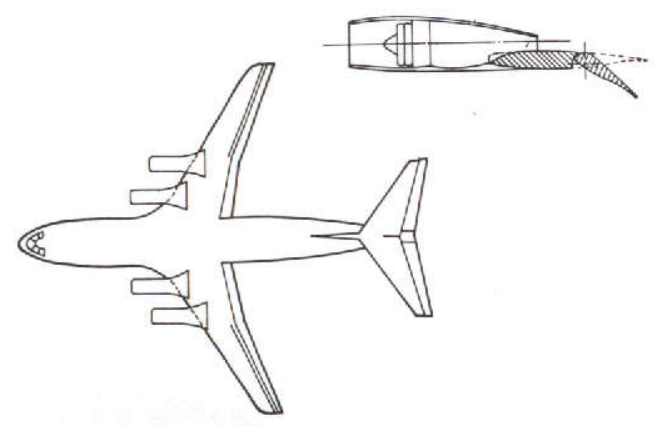

(b) ENGINE-OVER-THE-WING CONCEPT. CS-63139

Figure 1. - Externally-blown-flap airplane. 


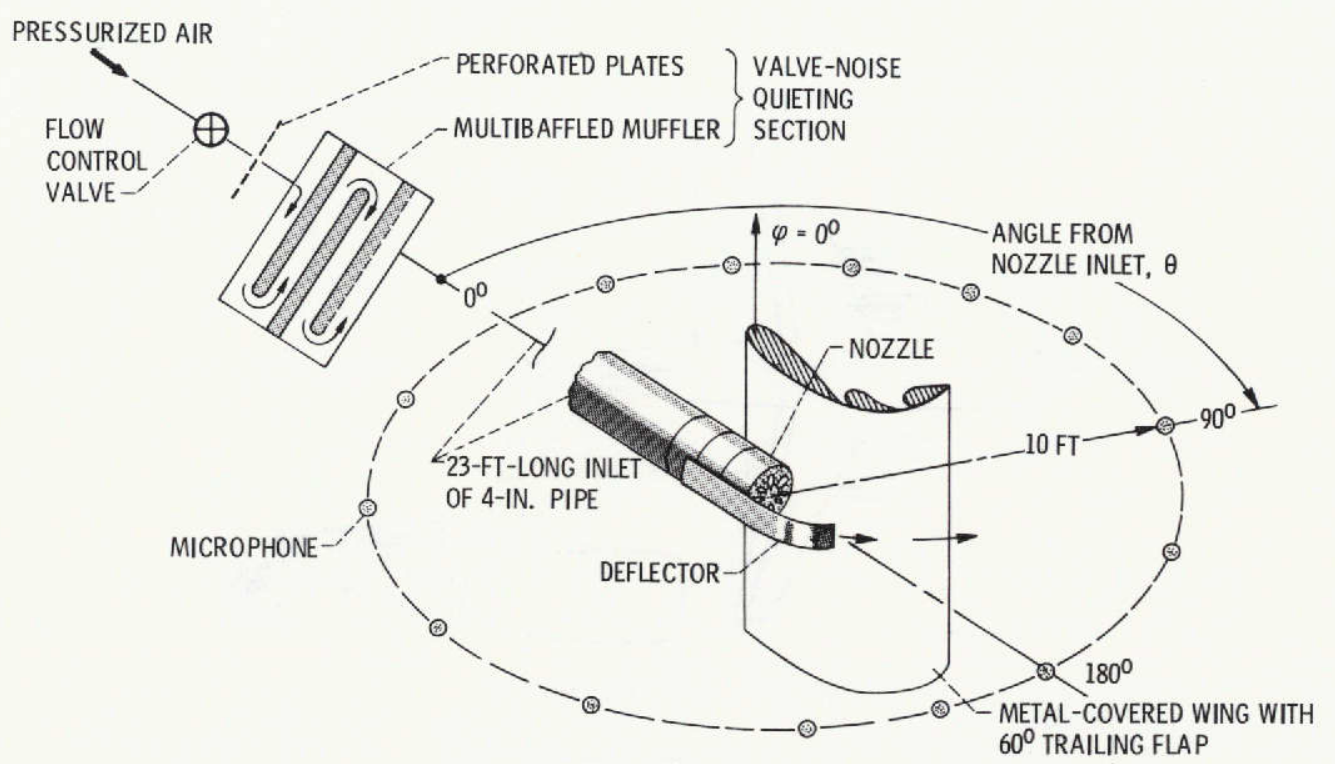

(a) FLOW SYSTEM AND MICROPHONE CIRCLE.

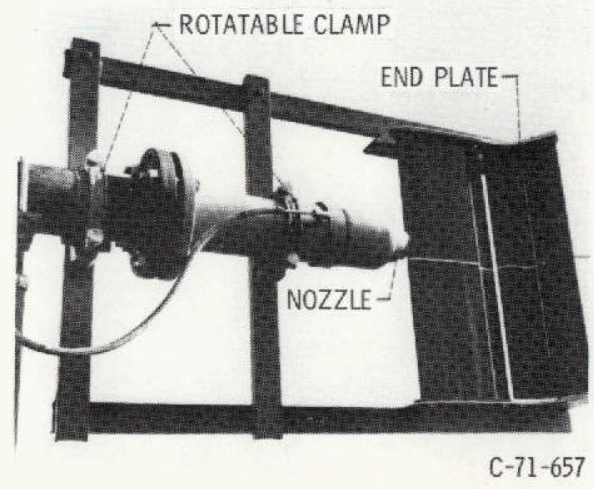

(b) TYPICAL UNDER-THE-WING MODEL.

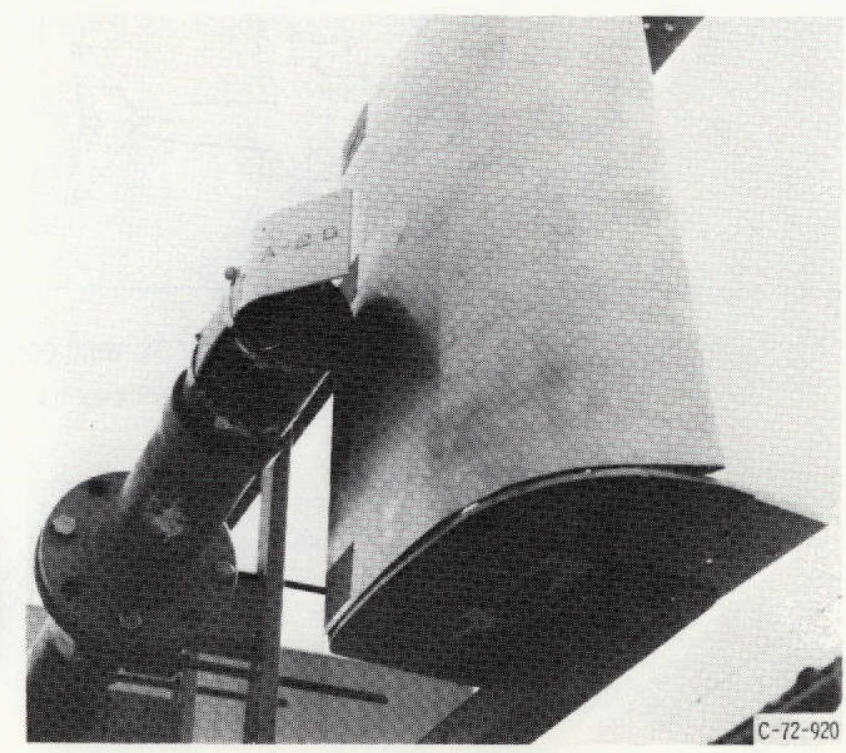

(c) TYPICAL OVER-THE-WING MODEL.

Figure 2, - Small-scale cold-flow externally blown flap noise test facility. 


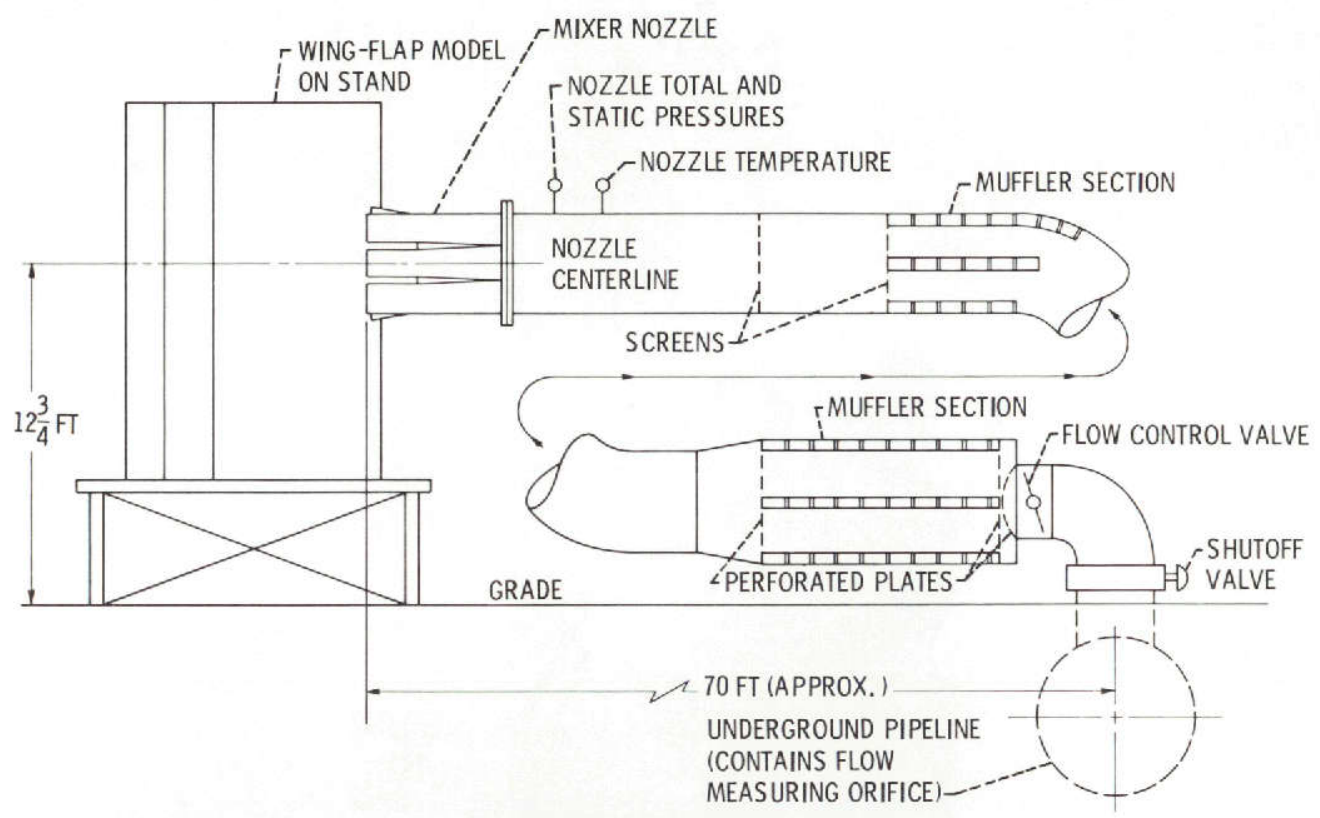

(a) AIR FLOW SYSTEM.

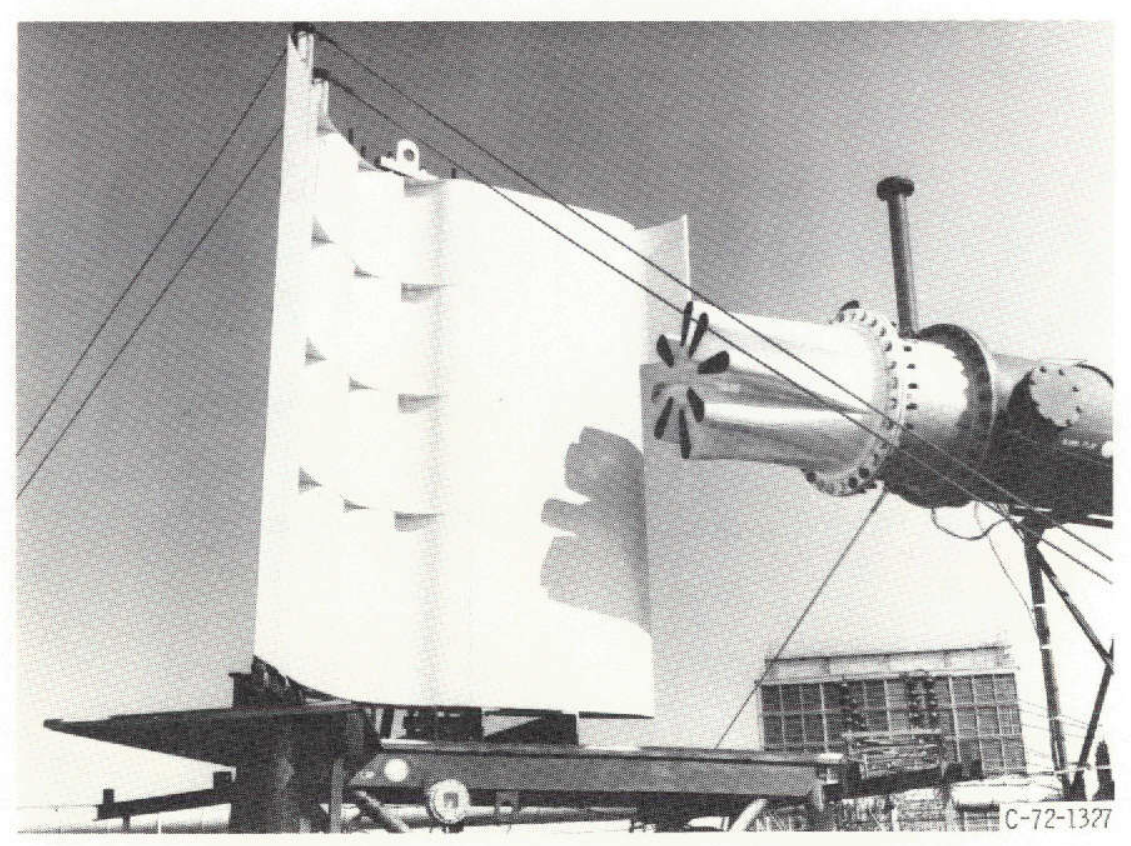

(b) TYPICAL UNDER-THE-WING MODEL WITH MIXER-DECAYER NOZZLE.

Figure 3. - Large-scale cold-flow externally blown flap noise test facility. 


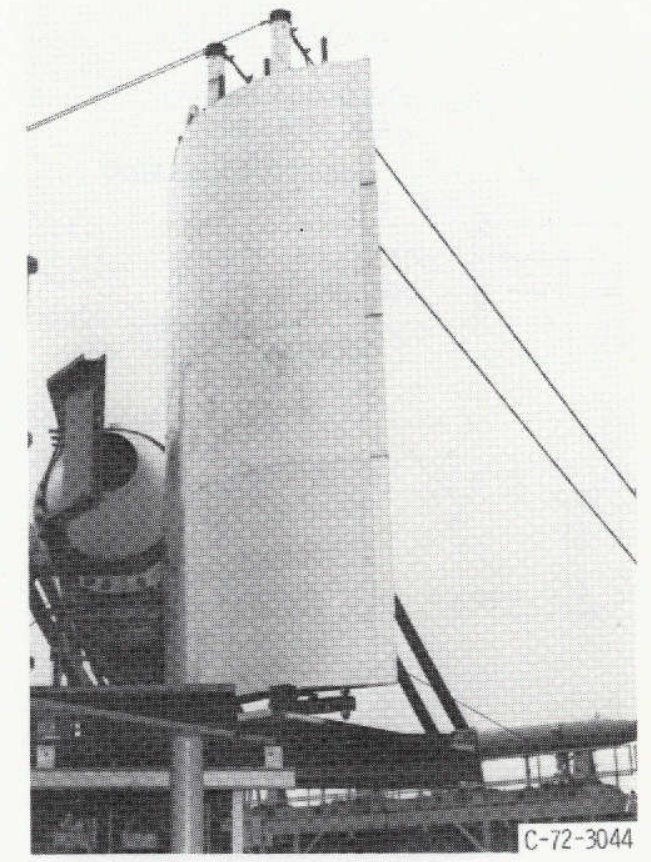

(c) OVER-THE-WING MODEL.

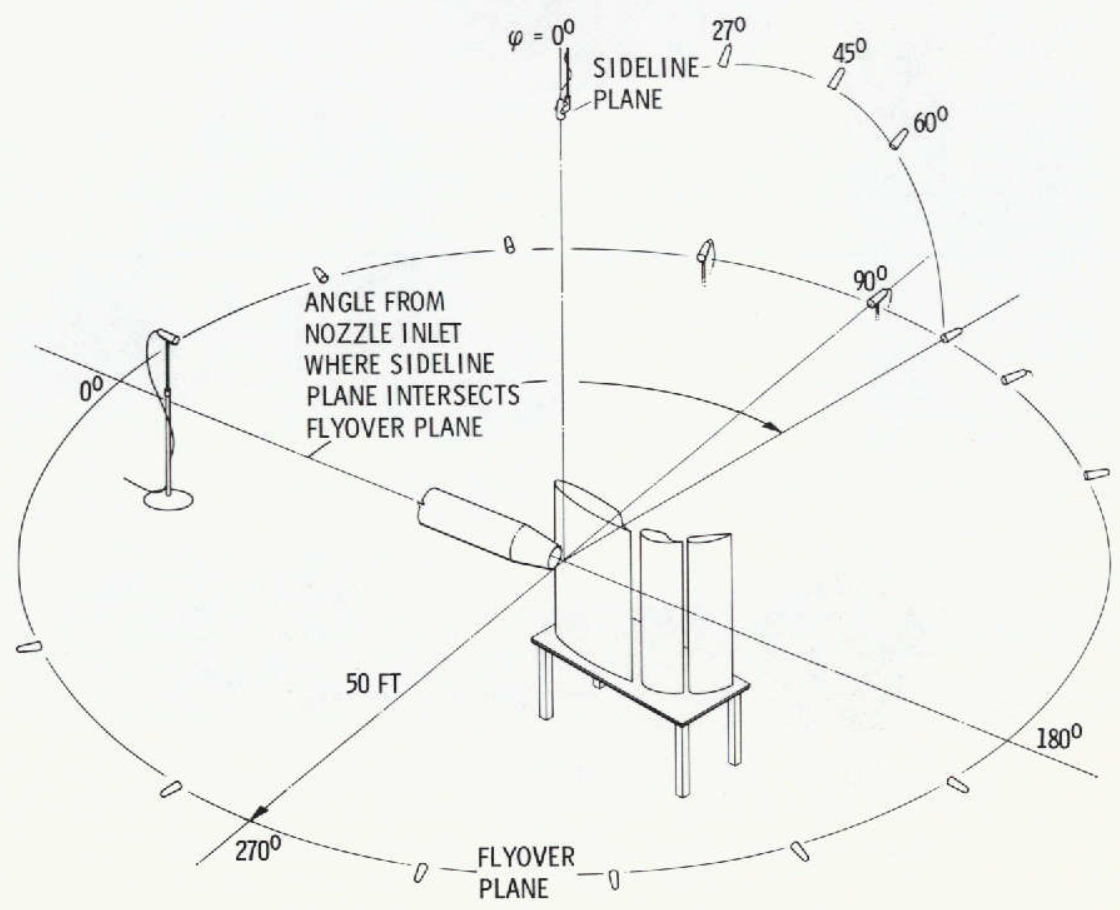

(d) MICROPHONE LAYOUT FOR TAKING FLYOVER AND SIDELINE MODE NOISE DATA.

Figure 3. - Concluded. 


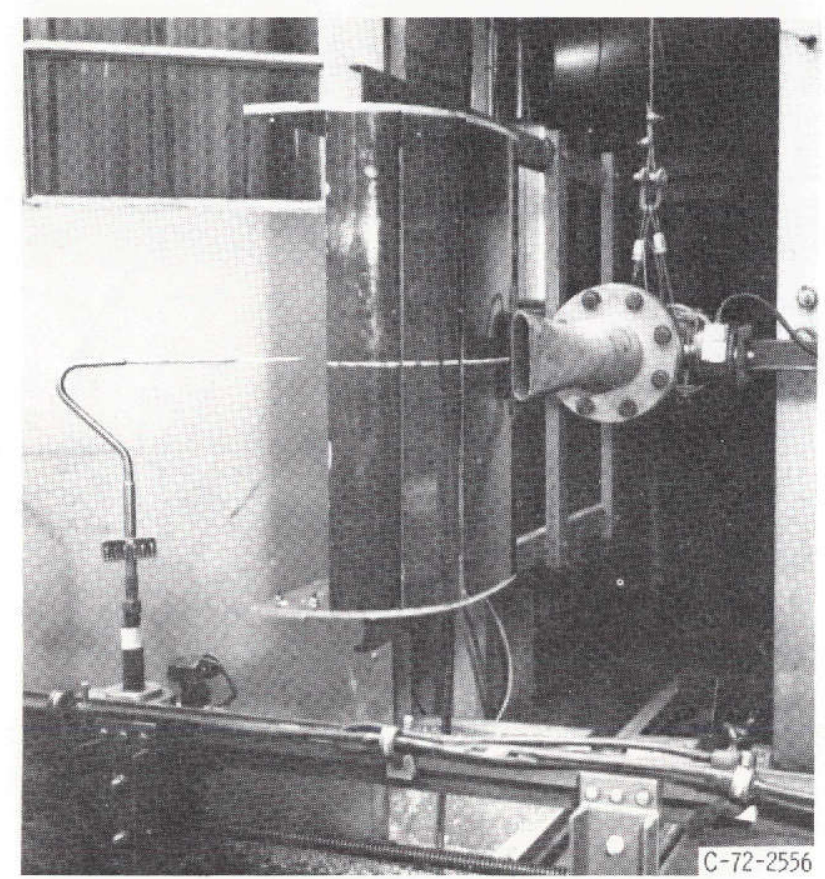

(a) OVER-THE-WING MODEL WITH A 5 TO I SLOT NOZZLE INSTALLED IN LIFT-THRUST RIG.

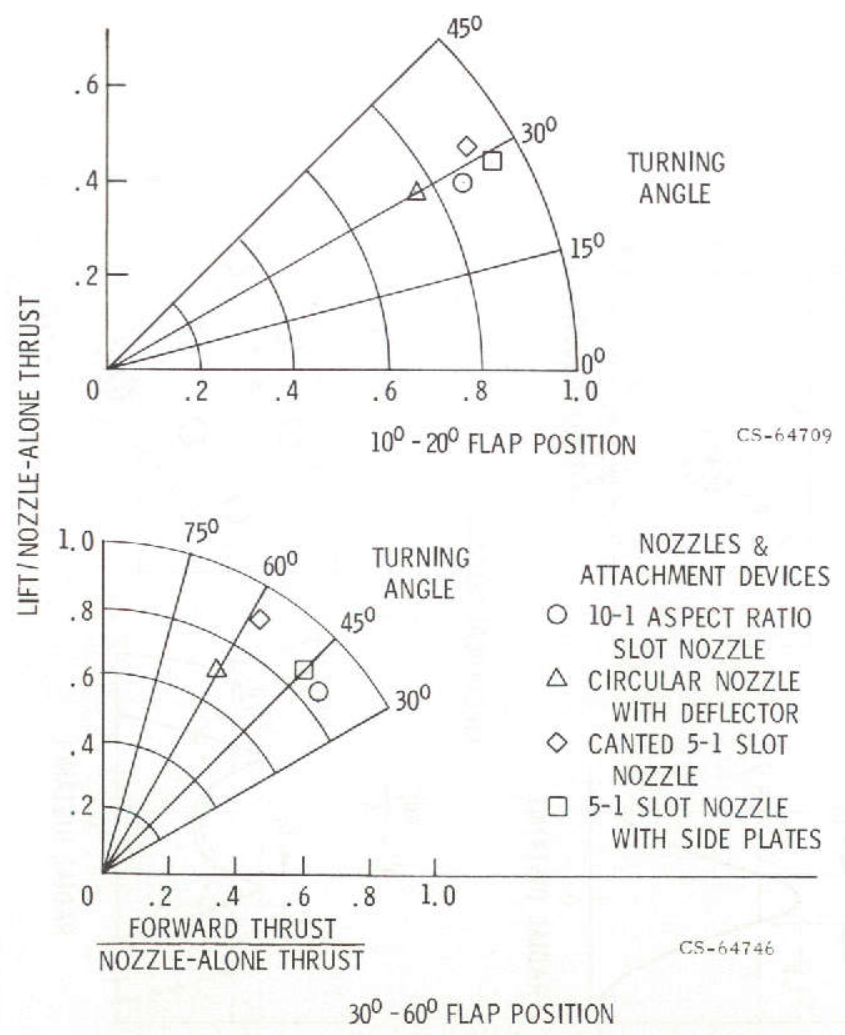

(b) MEASURED STATIC TURNING EFFECTIVENESS FOR SOME OVERTHE-WING EBF MODELS. FLAP SLOTS WERE COVERED.

Figure 4. - Small model lift and thrust measurements. 

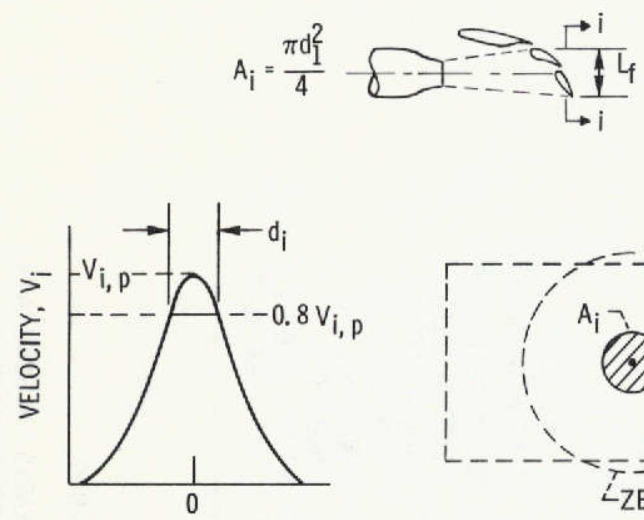

RADIAL DISTANCE

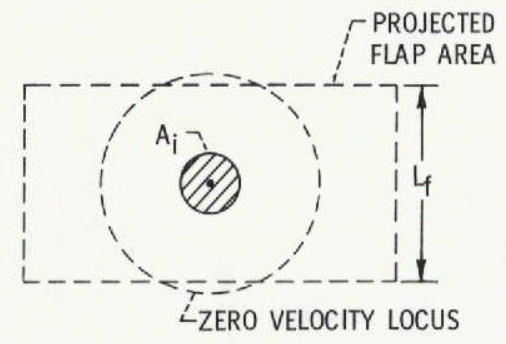

(a) CONICAL NOZZLE.

CS-69539

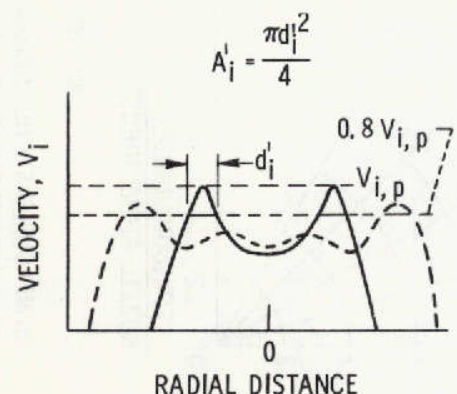

RADIAL DISTANCE

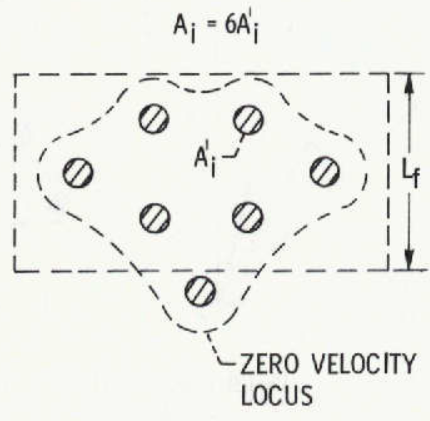

IMPINGEMENT AREAS ON FLAPS

CS- 69538 (b) SEVEN-LOBE MIXER NOZZLE (REF. 24).

Figure 5. - Typical exhaust flow impingement profiles with corresponding impingement parameters.

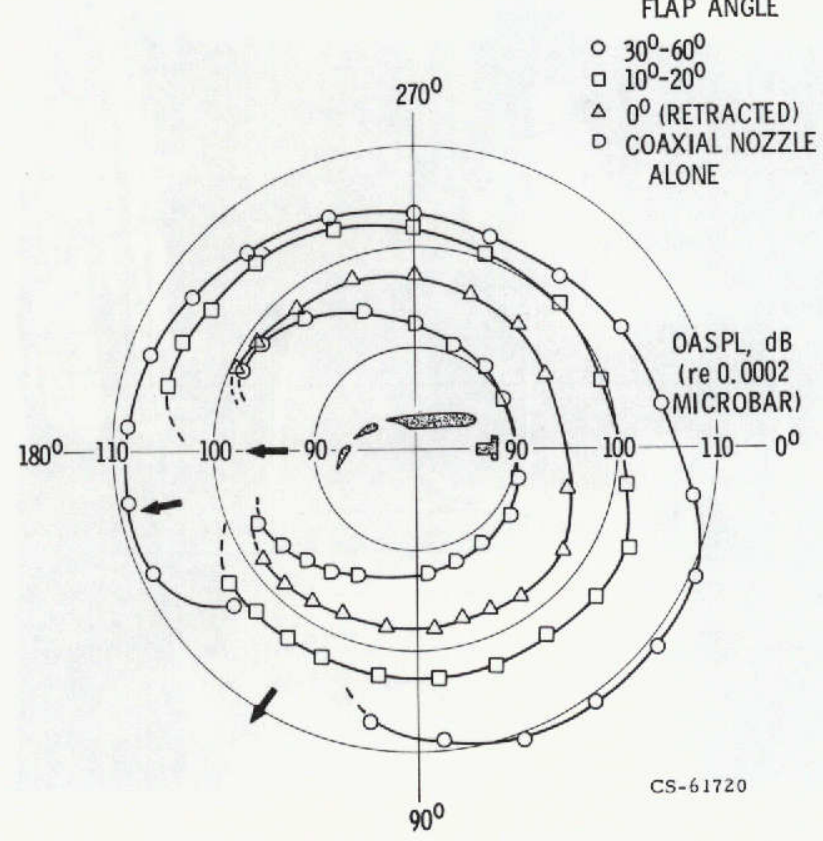

Figure 6. - Typical radiation patterns for externally blown flap noise. Flap angles, $30^{\circ}-60^{\circ}, 10^{\circ}-20^{\circ}$, and $0^{\circ}$, plus nozzle (pylon attached) alone. Exhaust velocities: core, $765 \mathrm{ft} / \mathrm{sec}$; and fan, $582 \mathrm{ft} / \mathrm{sec}$. Microphone radius, 50 feet. Model 1 of Table I. 


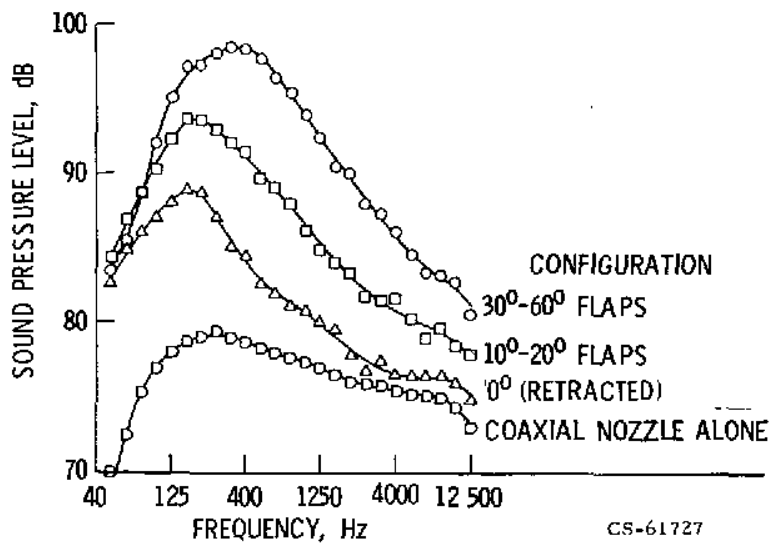

Figure 7. - Typical 1/3-octave spectra for flap noise for four test configurations of model 1 (Table I). Exhaust velocities: core, $765 \mathrm{ft} / \mathrm{sec}$; and fan, $582 \mathrm{ft} / \mathrm{sec}$. Microphone angle, $85^{\circ}$; distance, $50 \mathrm{ft}$.

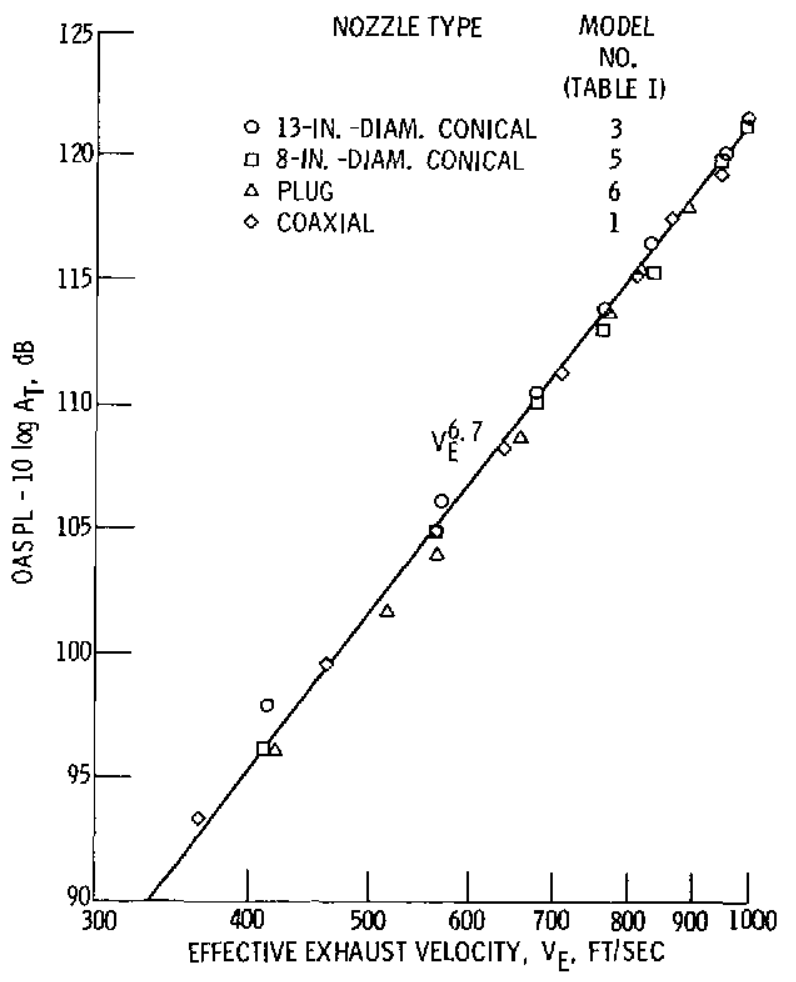

Figure 9. - Variation of normalized overall sound pressure level with nozzle exhaust velocity for 2-flap EBF configurations. Trailing flap angle, $60^{\circ}$; microphone distance, $50 \mathrm{ft}$; microphone angle, 700

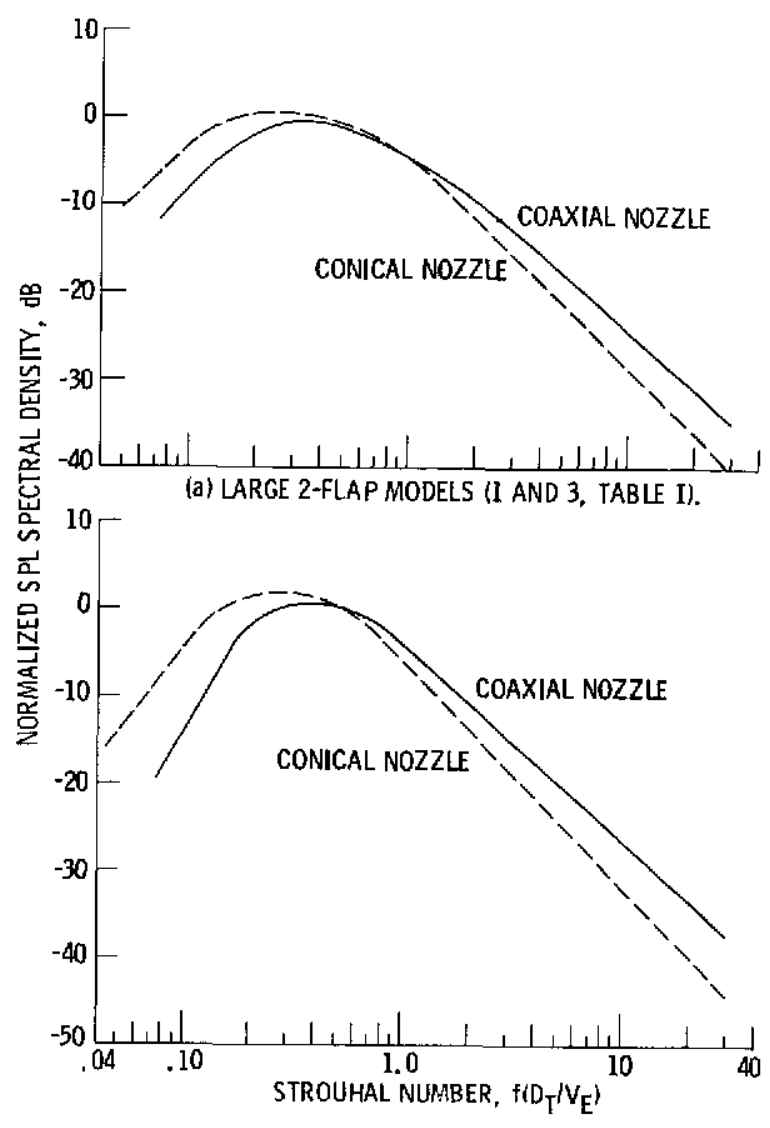

(b) LARGE 3-FLAP MODELS (2 AND 4, TABLE I).

Figure 8. - Strouhal correlations for 13-in. -diam. conical and coaxial nozzle configurations. Trailing flap angle, $60^{\circ}$; microphone angle, $70^{\circ}$.

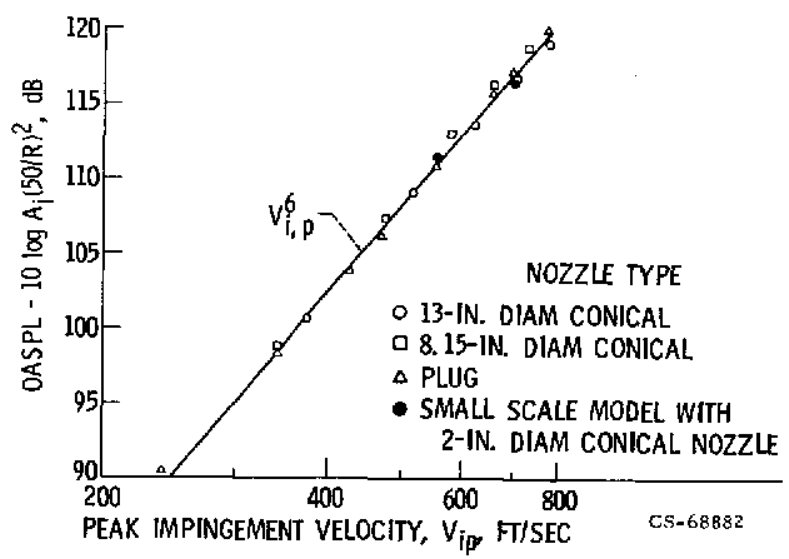

Figure 10. - Variation of normalized overall sound pressure level at radial peak angle with impingement velocity for 2-flap EBF configurations. Trailing flap angle, $60^{\circ}$; microphone distance, $50 \mathrm{ft}$. 


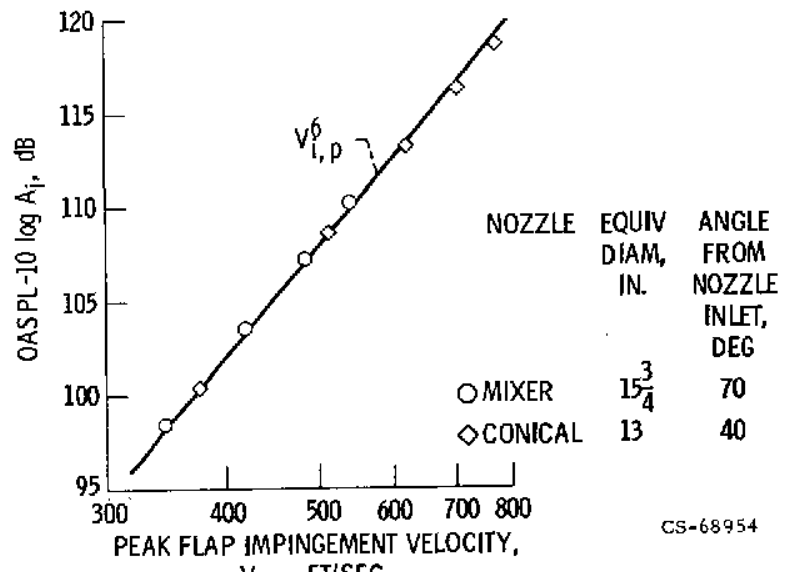

$V_{i, p}, F T / S E C$

Figure 11. - Normalized overall sound pressure at radial peak angle as a function of impingement velocity for a 7 -lobe mixer nozzle and conical nozzle. Trailing flap setting, $60^{\circ}$; microphone distance, $50 \mathrm{ft}$.

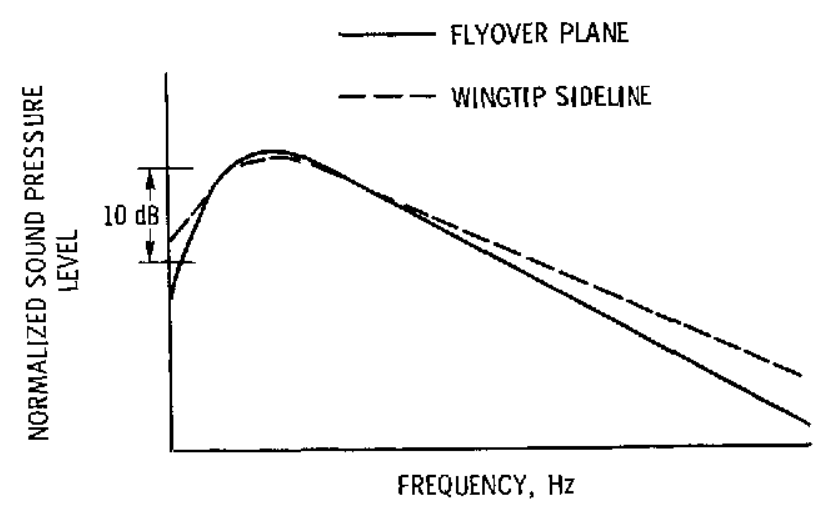

Figure 13. - Comparison of flyover and wingtip sideline spectral shapes at $90^{\circ}$ from inlet. Coaxjal nozzle UTW EBF configuration.

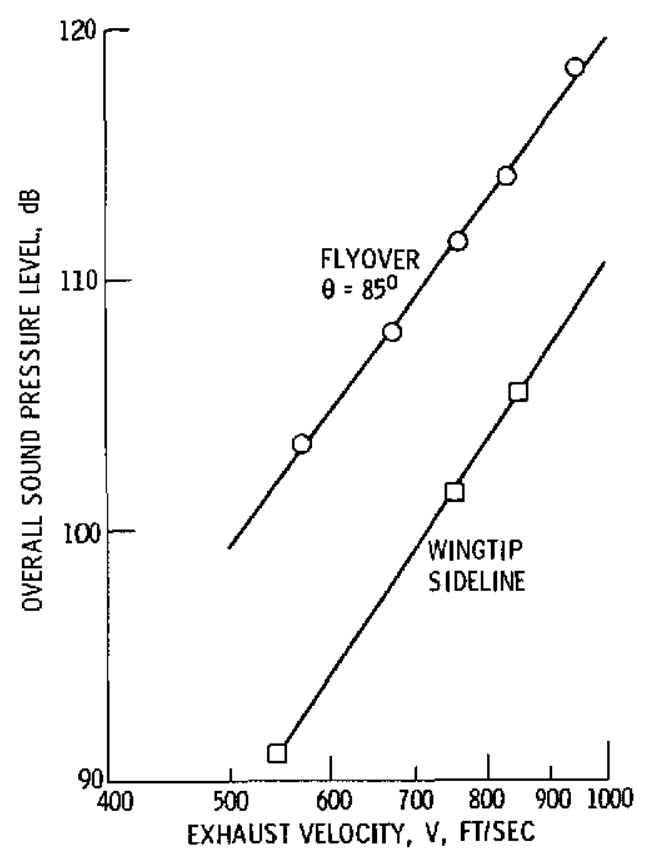

Figure 12. - Comparison of flap noise measured at wingtip sideline and $85^{\circ}$ flyover plane microphones. Distance, $50 \mathrm{ft}$. Trailing flap angle, $60^{\circ}$. Model 3 of Table I. 


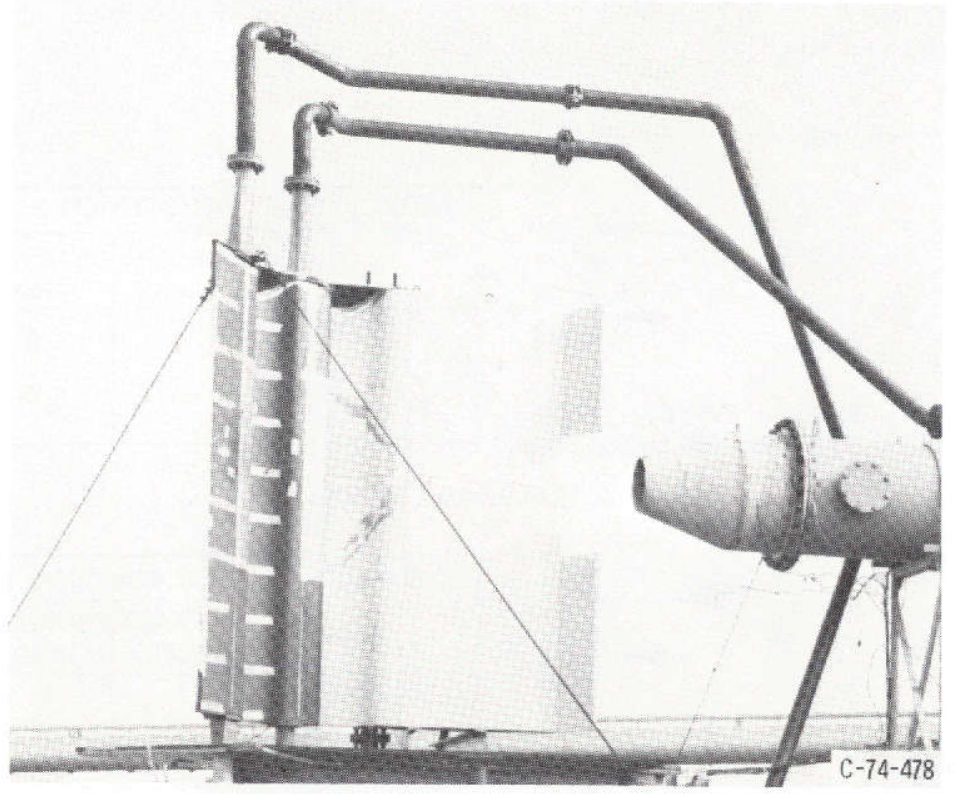

(a) TRAILING EDGE BLOWING. MODEL 3 OF TABLE II.

Figure 15. - Large-scale flap noise suppression model. Chord length, $7 \mathrm{ft}$; nozzle diameter, 13 in.; trailing flap angle, $60^{\circ}$.

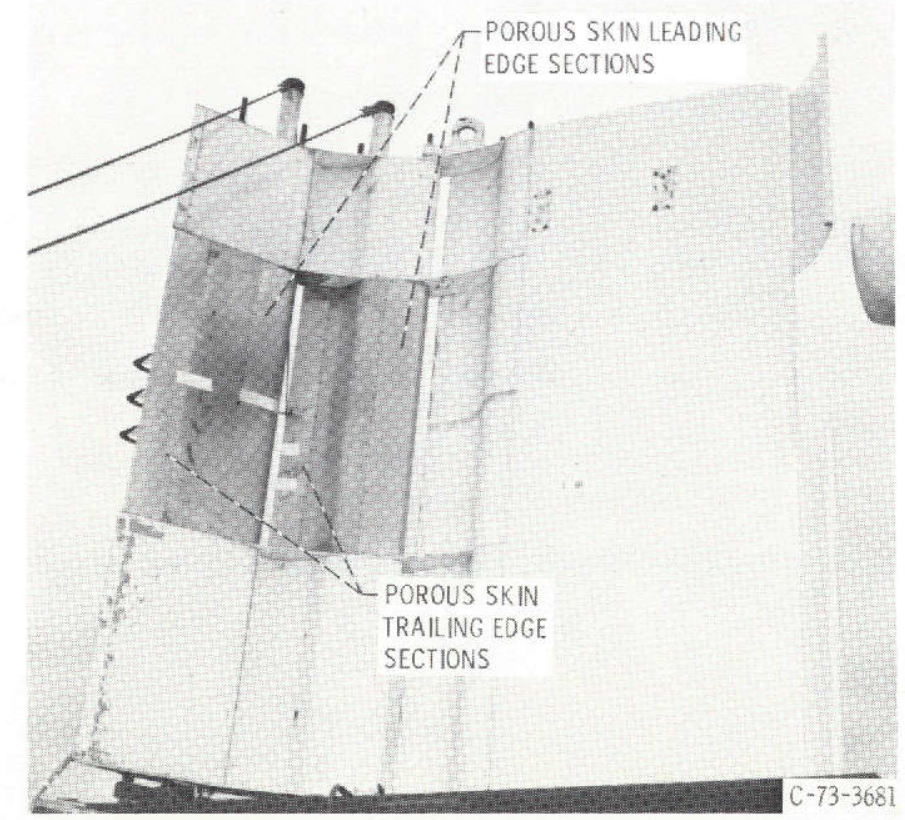

(b) POROUS LEADING AND TRAILING EDGES ON FLAPS. MODEL 2 OF TABLE II.

Figure 15. - Large-scale flap noise suppression model. Chord length, $7 \mathrm{ft}$; nozzle diameter, 13 in.; trailing flap angle, $60^{\circ}$. 


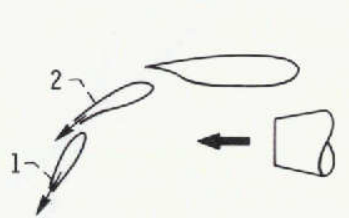

SLOT l: $1 \times 48$ IN.; 15\% NOZZLE FLOW SLOT 2: $1 / 2 \times 48$ IN.; $10 \%$ NOZZLE FLOW

\begin{tabular}{|c|c|c|c|}
\hline \multirow{2}{*}{$\begin{array}{l}\text { ACTIVE } \\
\text { SLOTS }\end{array}$} & \multirow{2}{*}{$\begin{array}{c}\text { FLAP } \\
\text { LEADING } \\
\text { EDGE }\end{array}$} & \multicolumn{2}{|c|}{ NOISE REDUCTION, $\triangle \mathrm{dB}$} \\
\hline & & $\begin{array}{c}\text { FORWARD } \\
\text { QUAD } \\
\end{array}$ & $\begin{array}{c}\text { REARWARD } \\
\text { QUAD }\end{array}$ \\
\hline 1 & SOLID & 0 & 0 \\
\hline 1,2 & POROUS & 3 & 2 \\
\hline
\end{tabular}

(a) TRAILING EDGE BLOWING.

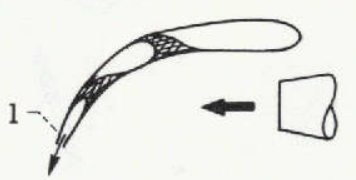

SLOT 1: 1 × 48 IN.; $15 \%$ NOZZLE FLOW

\begin{tabular}{|c|c|c|}
\hline \multirow{2}{*}{ ELEMENTS } & \multicolumn{2}{|c|}{ NOISE REDUCTION, $\Delta \mathrm{dB}$} \\
\cline { 2 - 3 } & $\begin{array}{c}\text { FORWARD } \\
\text { QUAD }\end{array}$ & $\begin{array}{c}\text { REARWARD } \\
\text { QUAD }\end{array}$ \\
\hline $\begin{array}{c}\text { SLOTS COVERED } \\
\text { SLOTS COVERED } \\
+ \text { T. E. BLOWING }\end{array}$ & 3 & 1 \\
\hline
\end{tabular}

(b) SLOTS PARTIALLY COVERED.

CS -69542

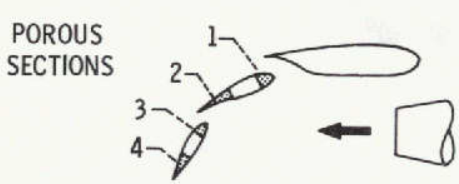

POROSITY, $15 \%$

\begin{tabular}{|l|c|c|}
\hline \multirow{2}{*}{$\begin{array}{c}\text { POROUS } \\
\text { SECTIONS }\end{array}$} & \multicolumn{2}{|c|}{ NOISE REDUCTION, $\triangle \mathrm{dB}$} \\
\cline { 2 - 3 } & $\begin{array}{c}\text { FORWARD } \\
\text { QUAD }\end{array}$ & $\begin{array}{c}\text { REARWARD } \\
\text { QUAD }\end{array}$ \\
\hline 1 TO 4 & $2 \frac{1}{2}$ & -2 TO $+1 \frac{1}{2}$ \\
2,3 & 2 & -2 TO $+1 \frac{1}{2}$ \\
\hline
\end{tabular}

(c) POROUS SURFACES.

\begin{tabular}{|c|c|c|c|}
\hline \multirow{2}{*}{ TREATMENT } & \multicolumn{2}{|c|}{ NOISE REDUCTION, $\triangle \mathrm{dB}$} & LOSS \\
\cline { 2 - 3 } & $\begin{array}{c}\text { FORWARD } \\
\text { QUAD }\end{array}$ & $\begin{array}{c}\text { REARWARD } \\
\text { QUAD }\end{array}$ & LIFT \\
\hline SCREEN ONLY & 2 & 2 TO 3 & $\approx 30 \%$ \\
\hline $\begin{array}{c}\text { SCREEN PLUS } \\
\text { ACTIVE SECTIONS } \\
1 \text { TO } 4 \text { ABOVE }\end{array}$ & $2 \frac{1}{2}$ & 2 TO 4 & $\approx 40 \%$ \\
\hline
\end{tabular}

(d) SCREEN AND SCREEN PLUS POROUS SECTIONS.

Figure 16. - Typical externally blown flap noise suppression test results. 


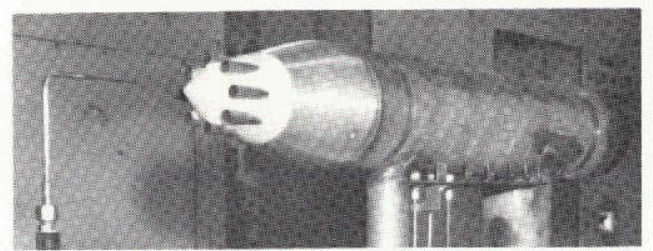

(a) 8-TUBE MIXER NOZZLE IN $6 \times 9$ FT TUNNEL.

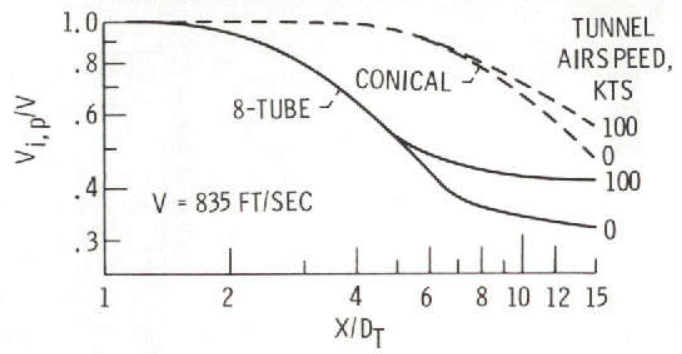

(b) PEAK VELOCITY DECAY.

Figure 17. - Effect of forward airspeed on nozzle exhaust velocity decay. Data are for an 8 -tube mixer nozzle and a conical nozzle. Nominal nozzle diameter, 2 in. Nozzle exhaust velocity, $835 \mathrm{ft} / \mathrm{sec}$.

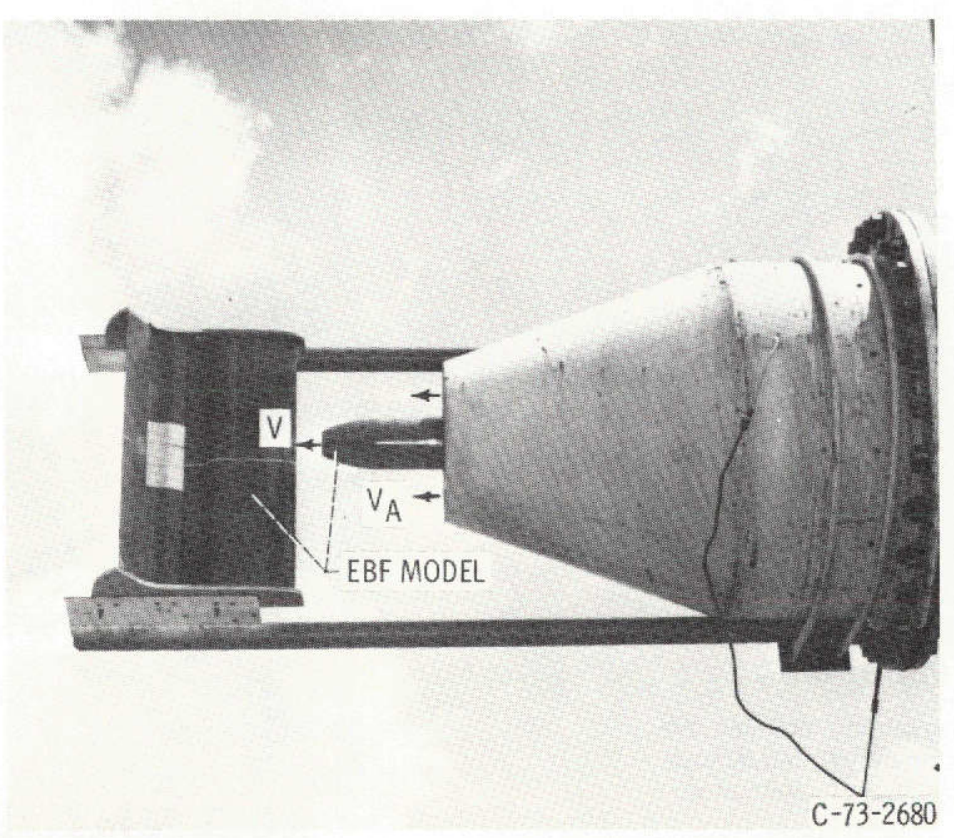

Figure 18. - Externally blown flap airspeed-effect test. Free-jet diameter, 13 in. EBF model shown has 13 in. wing chord and 2 in. diameter conical nozzle. 


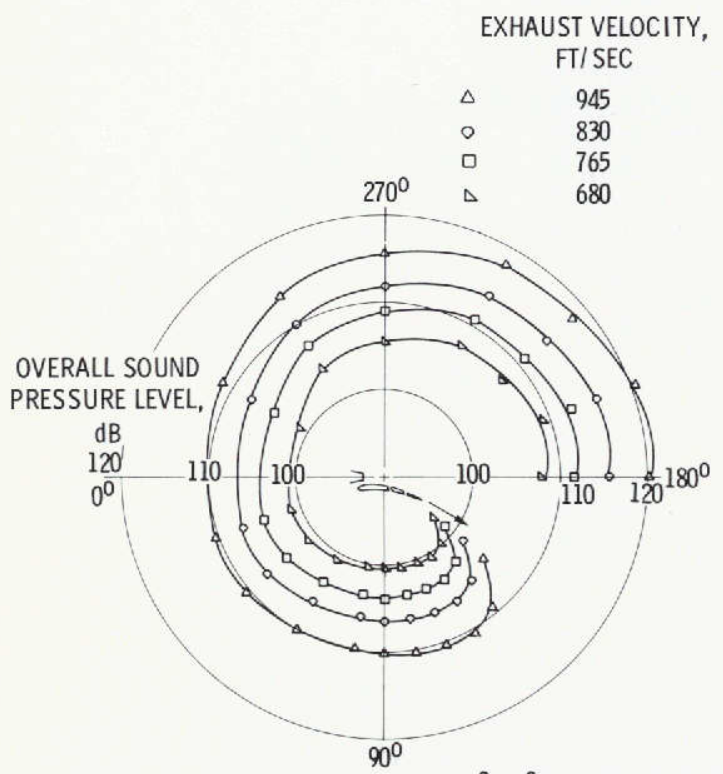

(a) FLAP POSITION, $10^{\circ}-20^{\circ}$.

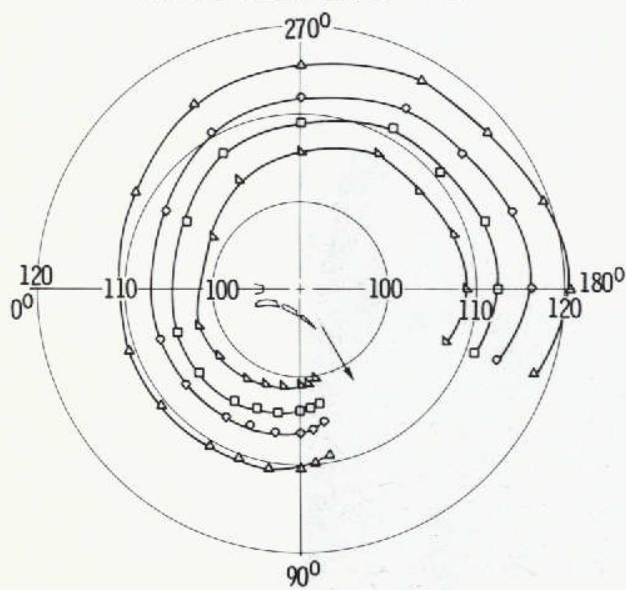

(b) FLAP POSITION, $30^{\circ}-60^{\circ}$.

Figure 19. - Flap noise radiation patterns for 7 -foot chord OTW EBF model with a 13-inch diameter conical nozzle with flow deflector. Model 17 of Table I. Microphone distance, $50 \mathrm{ft}$.
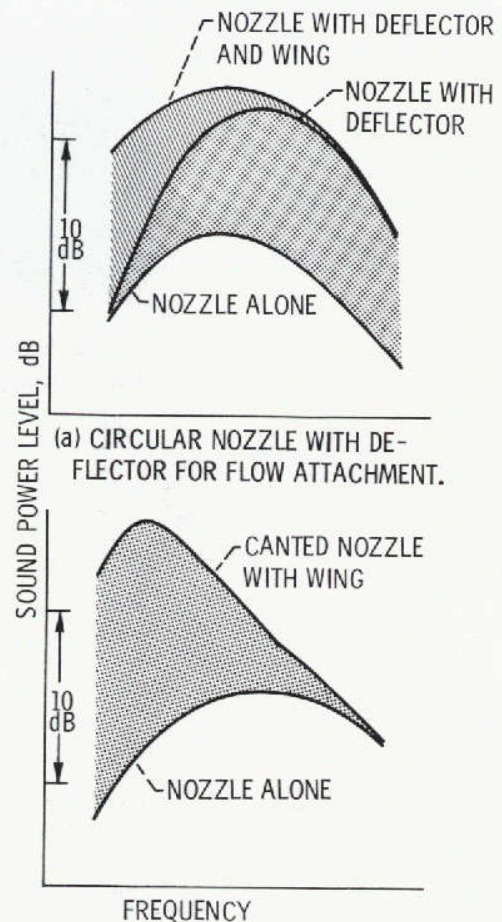

(b) CANTED 10-1 SLOT NOZZLE, NO DEFLECTOR.

Figure 20. - Comparison of noise generation for two engine-overthe-wing concepts.

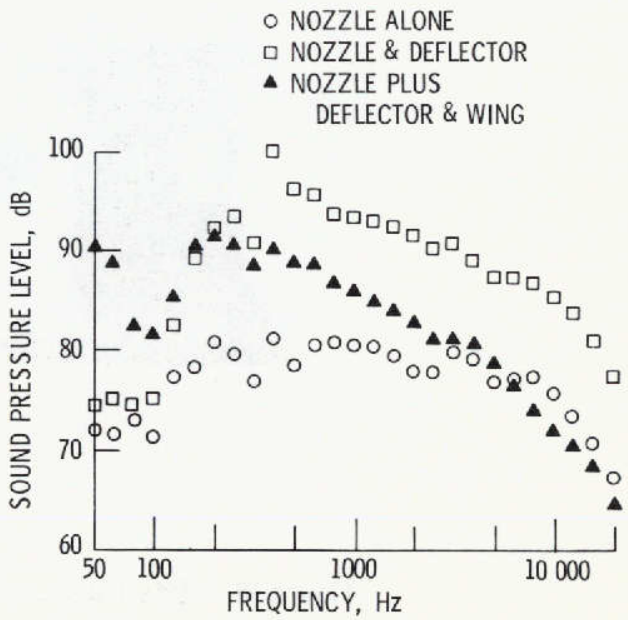

Figure 21. - Flap noise spectra at $90^{\circ}$ from inlet for large OTW model with 13-inch diameter conical nozzle and deflector. Distance, $50 \mathrm{ft}$; trailing flap angle, $60^{\circ}$; exhaust velocity, $680 \mathrm{ft} / \mathrm{sec}$. 


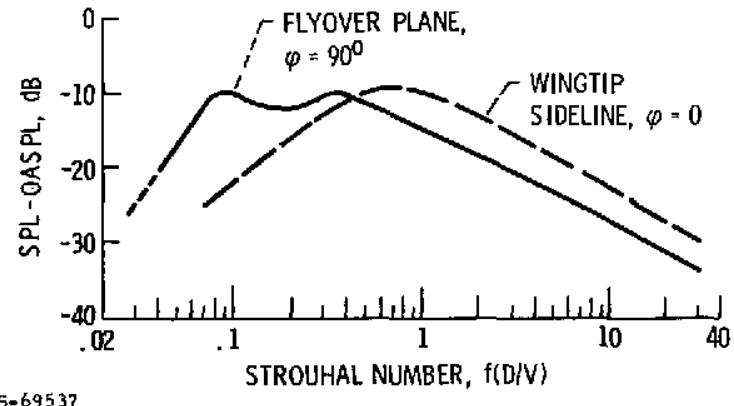

Figure 22. - Normalized sound pressure level one-thirdoctave spectra for large OTW EBF model. Microphone angle, $\theta, 100^{\circ}$. Trailing flap angle, $20^{\circ}$. Data corrected for ground reflections.

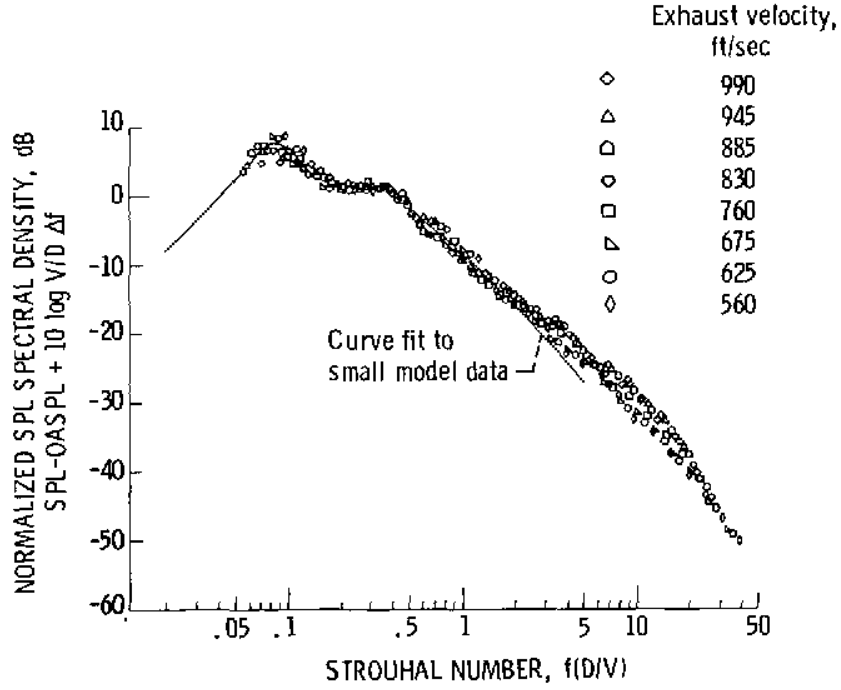

Figure 23. - Strouha! correlations of large model OTW flap noise data. Trailing flap angle, $20^{0}$; microphone angle, $100^{\circ}$. Data corrected for ground reflections. Small model correlation curve shown for comparison.

$\triangle$ LARGE MODEL (13 IN. DIAM NOZZLE)

- SCALED UP FROM SMALL MODEL

(2 IN. DIAM NOZZLE)

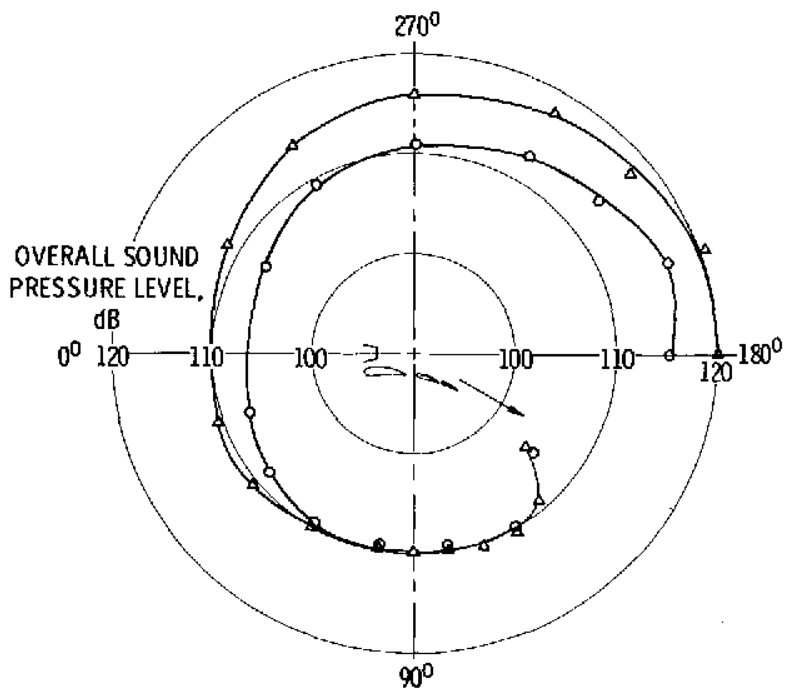

Figure 24. - Comparison of large OTW model data with scaled up small model (18, Table I) results. Trailing flap angle, $20^{\circ}$; nozzle exhaust velocity, $945 \mathrm{ft} / 5 \mathrm{ec}$; microphone distance, $50 \mathrm{ft}$ 

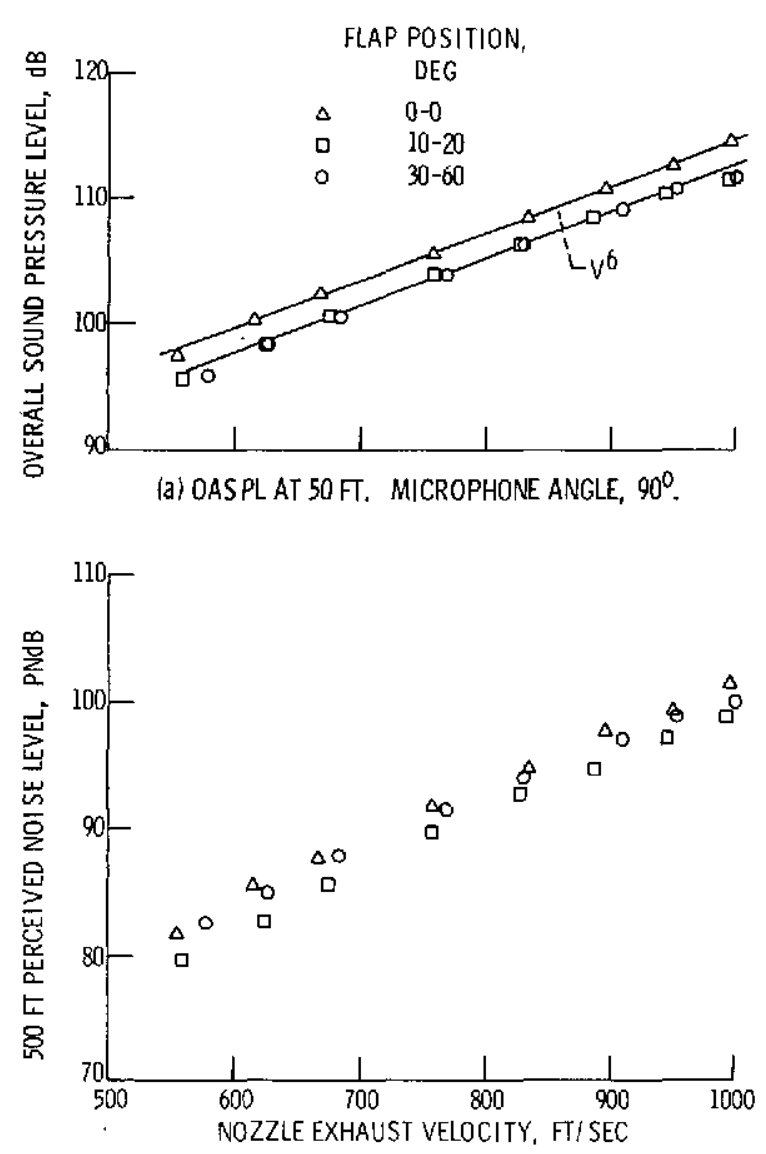

(b) PERCEIVED NOI SE LEVEL AT 500 FT AT MICROPHONE ANGLE PRODUCING FLYOVER MAXIMUM.

Figure 25. - Effect of nozzle exhaust velocity on noise level in the flyover plane for the large OTW model.

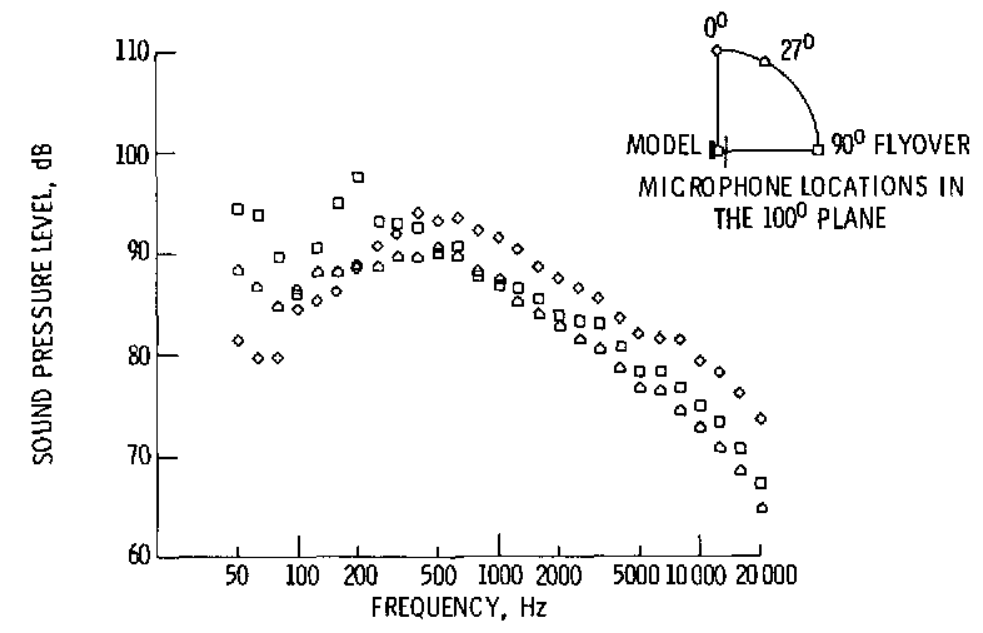

(a) 1/3-OCTAVE SPECTRA AT 50 FT. NOZZLE EXHAUST VELOCITY, $760 \mathrm{FT} / \mathrm{SEC}$

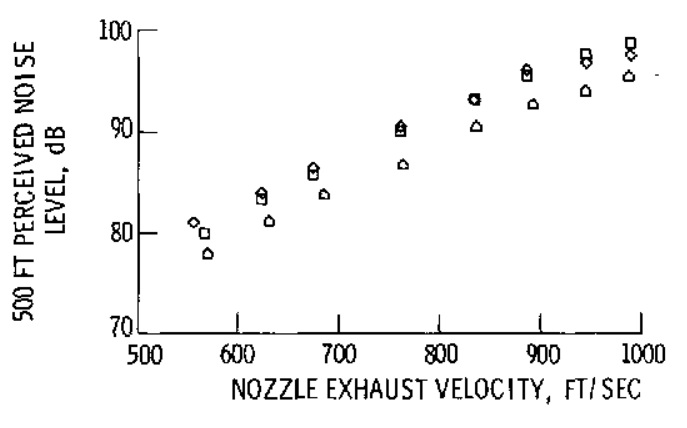

(b) PERCEIVED NOISE LEVEL AT $500 \mathrm{FT}$.

Figure 26. - Comparison of large OTW flap noise levels measured with sideline microphones to noise measured in flyover plane. Trailing flap angle, $20^{\circ}$; microphones located in the $100^{\circ}$ plane. 


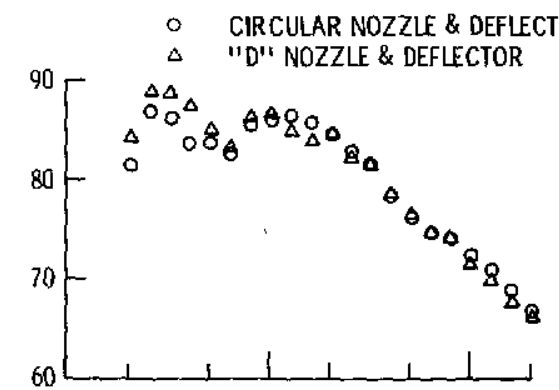

(a) NOZZLE EXHAUST VELOCITY, 625 FT/SEC.

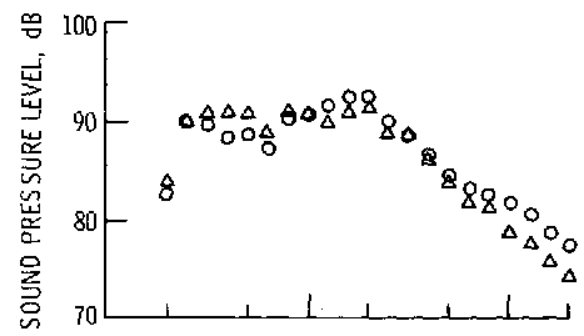

(b) NOZZLE EXHAUST VELOCITY, $765 \mathrm{FT} / \mathrm{SEC}$.

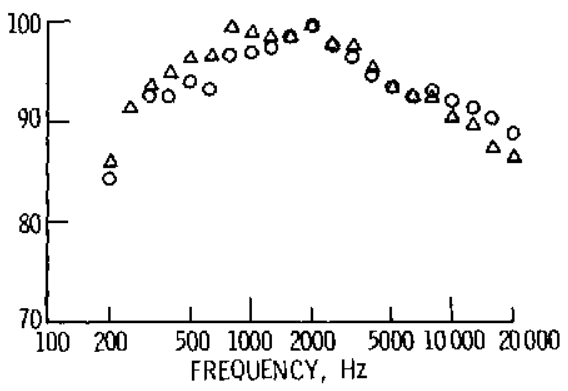

(c) NOZZLE EXHAUST VELOCITY, $945 \mathrm{FT} / \mathrm{SEC}$.

Figure 27. - Comparison of 1/3-octave spectra for circular nozzle and "D" nozzle configurations. Deflector attached. Microphone angle, $100^{\circ}$. Flap position, $10^{\circ}-20^{\circ}$. Microphone distance, $10 \mathrm{ft}$.

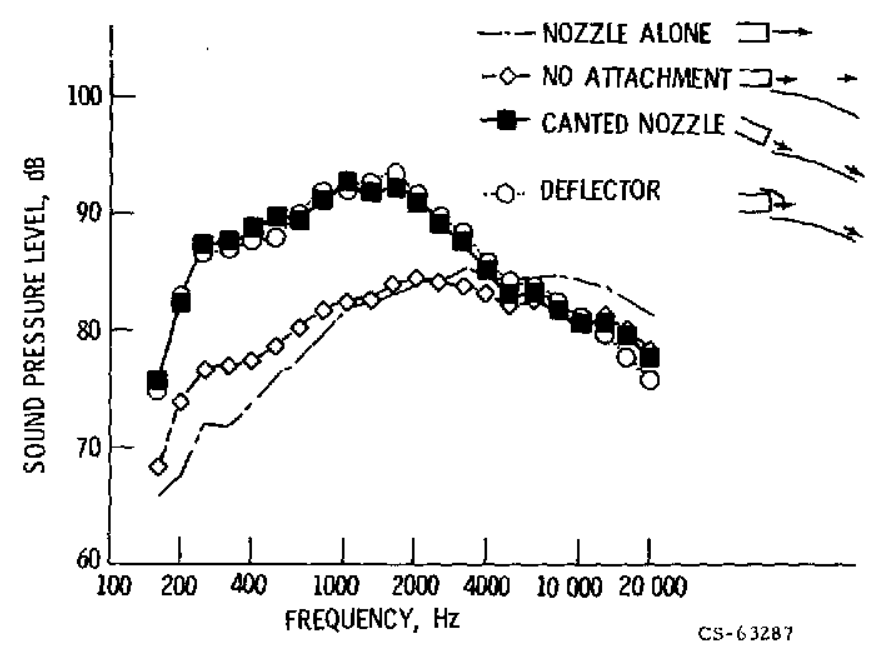

Figure 28. - Comparison of noise spectra for small cylindrical nozzle OTW models. Microphone angle, $120^{\circ}$; trailing flap angle, $20^{\circ}$; exhaust velocity, $750 \mathrm{fts}$ sec.

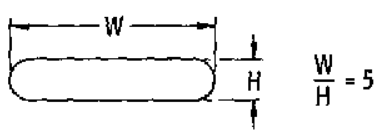

ATTACHMENT DEVICE

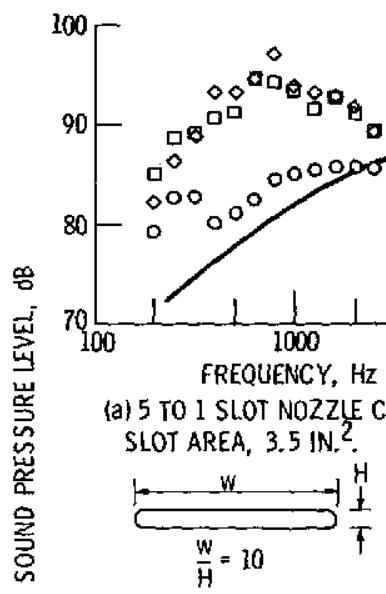

ATTACHMENT DEVICE

$\begin{array}{ll}- & \text { CANTED NOZZLE } \\ \circ & \text { SIDEPLATES } \\ \circ & \text { NO DEVICE }\end{array}$

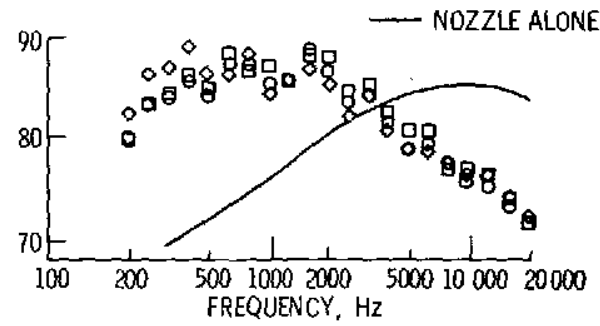

(b) 10 TO 1 SLOT NOZZZLE CONFIGURATION. SLOT AREA, 2.1 IN.?

Figure 29. - Effect of aftachment device on noise spectra for small OTW models with slot nozzles. Trailing flap angle, $20^{\circ}$. Microphone angle, $120^{\circ}$. Distance, $10 \mathrm{ft}$. Nozzle exhaust velocity, $750 \mathrm{ft} / \mathrm{sec}$. 

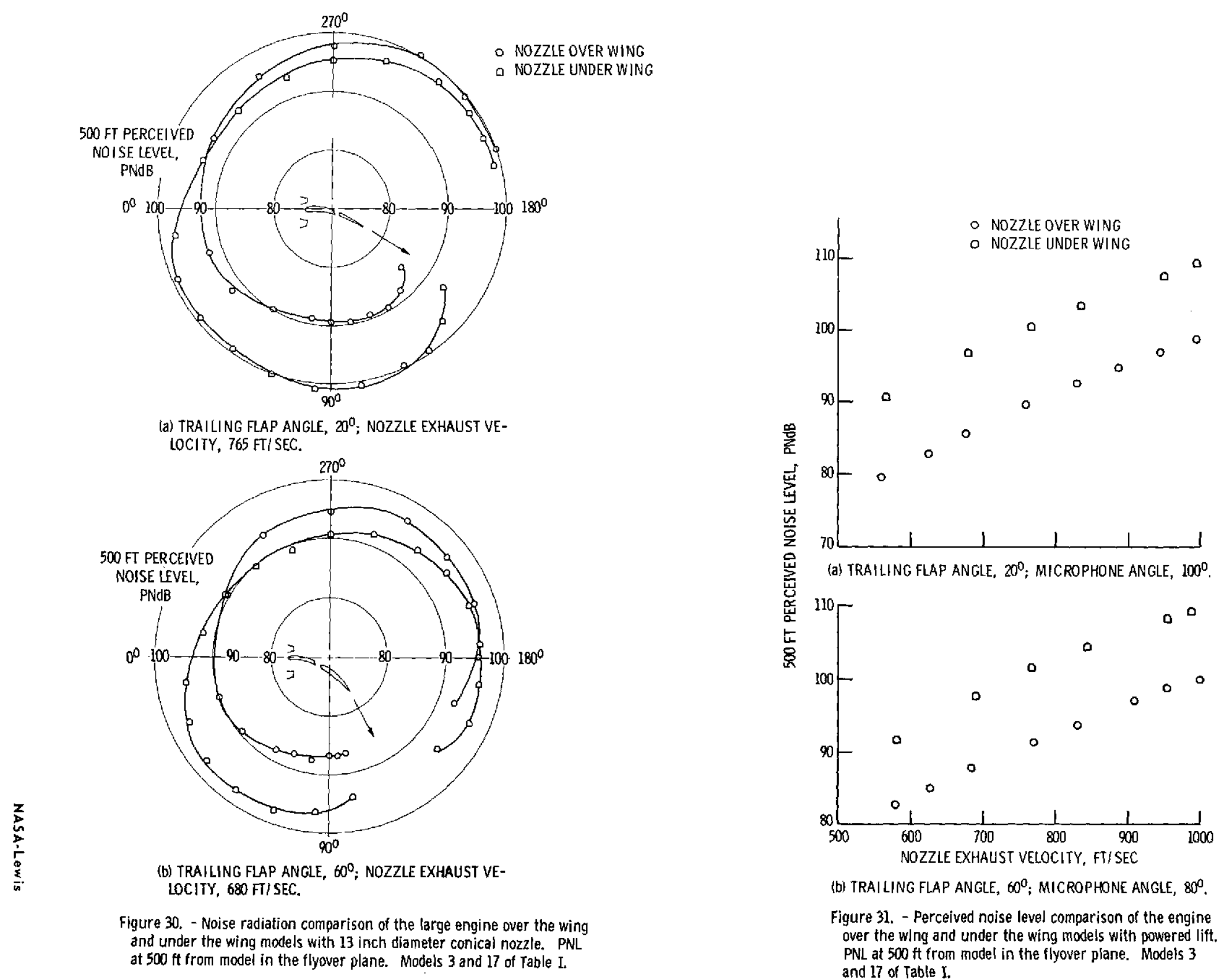

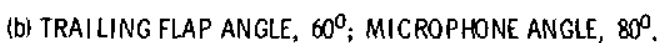

Figure 31. - Perceived noise level comparison of the engine over the wIng and under the wing models with powered lift. PNL at $500 \mathrm{ft}$ from model in the flyover plane. Models 3 and 17 of Table I. 